OPEN ACCESS

Edited by:

Antonio Lupini,

Mediterranea University of Reggio

Calabria, Italy

Reviewed by:

Xiaorong Fan,

Nanjing Agricultural University, China

Sasan Aliniaeifard,

University of Tehran, Iran

*Correspondence:

Jun-Wen Chen

cjw31412@163.com

Specialty section:

This article was submitted to

Plant Nutrition,

a section of the journal

Frontiers in Plant Science

Received: 18 October 2021

Accepted: 13 January 2022

Published: 15 February 2022

Citation:

Cun Z, Wu H-M, Zhang J-Y, Shuang S-P, Hong J and Chen J-W

(2022) Responses of Linear and Cyclic Electron Flow to Nitrogen

Stress in an N-Sensitive Species

Panax notoginseng.

Front. Plant Sci. 13:796931. doi: 10.3389/fpls.2022.796931

\section{Responses of Linear and Cyclic Electron Flow to Nitrogen Stress in an N-Sensitive Species Panax notoginseng}

\author{
Zhu Cun 1,2,3, Hong-Min Wu 1,2,3, Jin-Yan Zhang 1,2,3, Sheng-Pu Shuang 1,2,3, Jie Hong 1,2,3 and \\ Jun-Wen Chen ${ }^{1,2,3 *}$

\begin{abstract}
${ }^{1}$ College of Agronomy and Biotechnology, Yunnan Agricultural University, Kunming, China, ${ }^{2}$ Key Laboratory of Medicinal Plant Biology of Yunnan Province, Yunnan Agricultural University, Kunming, China, ${ }^{3}$ National \& Local Joint Engineering Research Center on Germplasm Innovation \& Utilization of Chinese Medicinal Materials in Southwestern China, Yunnan Agricultural University, Kunming, China
\end{abstract}

Nitrogen $(\mathrm{N})$ is a primary factor limiting leaf photosynthesis. However, the mechanism of N-stress-driven photoinhibition of the photosystem I (PSI) and photosystem II (PSII) is still unclear in the $\mathrm{N}$-sensitive species such as Panax notoginseng, and thus the role of electron transport in PSII and PSI photoinhibition needs to be further understood. We comparatively analyzed photosystem activity, photosynthetic rate, excitation energy distribution, electron transport, OJIP kinetic curve, P700 dark reduction, and antioxidant enzyme activities in low $N(L N)$, moderate $N(M N)$, and high $N(H N)$ leaves treated with linear electron flow (LEF) inhibitor [3-(3,4-dichlorophenyl)-1,1-dimethyl urea (DCMU)] and cyclic electron flow (CEF) inhibitor (methyl viologen, MV). The results showed that the increased application of $\mathrm{N}$ fertilizer significantly enhance leaf $\mathrm{N}$ contents and specific leaf $N(S L N)$. Net photosynthetic rate $\left(P_{n}\right)$ was lower in $H N$ and $L N$ plants than in $M N$ ones. Maximum photochemistry efficiency of PSII $\left(F_{\mathrm{v}} / F_{\mathrm{m}}\right)$, maximum photo-oxidation $\mathrm{P} 700^{+}\left(P_{\mathrm{m}}\right)$, electron transport rate of PSI (ETRI), electron transport rate of PSII (ETRII), and plastoquinone $(P Q)$ pool size were lower in the $L N$ plants. More importantly, K phase and CEF were higher in the LN plants. Additionally, there was not a significant difference in the activity of antioxidant enzyme between the MV- and $\mathrm{H}_{2} \mathrm{O}$-treated plants. The results obtained suggest that the lower LEF leads to the hindrance of the formation of $\Delta \mathrm{pH}$ and ATP in LN plants, thereby damaging the donor side of the PSIl oxygenevolving complex (OEC). The over-reduction of PSI acceptor side is the main cause of PSI photoinhibition under LN condition. Higher CEF and antioxidant enzyme activity not only protected PSI from photodamage but also slowed down the damage rate of PSII in $P$. notoginseng grown under $L N$.

Keywords: nitrogen, photoinhibition, photoprotection, electron transport, Panax notoginseng

\section{INTRODUCTION}

Photosynthesis is one of the most important physiological and biochemical reactions in nature (Berry et al., 2013; Martin et al., 2018). Nitrogen (N) is regarded as a necessary component of numerous biomolecules, such as Rubisco (Ribulose-1,5-bisphosphate carboxylase/oxygenase), chlorophyll (Chl), and photosynthetic proteins (Evans and Clarke, 2019). Photosynthetic capacity 
is closely related to leaf $\mathrm{N}$ content (Makino and Osmond, 1991). The $\mathrm{N}$ fertilizer application might increase $\mathrm{N}$ content, light harvesting capacity, and $P_{\mathrm{n}}$ (net photosynthetic rate) of leaves (Evans and Clarke, 2019). This has been confirmed by the performance observed in Oryza sativa and Arabidopsis thaliana grown under high $\mathrm{N}(\mathrm{HN})$ application (Perchlik and Tegeder, 2018; Hou et al., 2019). However, plants exposed to long-term $\mathrm{N}$ deficiency would suffer an imbalance between the capability for absorbing light energy and consuming this excess light energy, resulting in the generation of reactive oxygen species (ROS) (Yamori et al., 2016; Che et al., 2020; Mu and Chen, 2021). Photosystem II (PSII) is susceptible to HN and low N (LN) (Cisse et al., 2020; Zhang Z. et al., 2021). HN and LN can inhibit either on the acceptor side or on the donor side of PSII, resulting in damaging PSII functions. The donor side of PSII in Porphyridium cruentum, O. sativa, and Vitis labrusca were seriously impacted by $\mathrm{N}$ deficiency, leading to the inactivation of the oxygen-evolving complex (OEC) and the reduced photochemical efficiency (Chen and Cheng, 2003; Zhao et al., 2017; Tantray et al., 2020). HN supply increases the PSII photoinhibition in O. sativa and Chenopodium quinoa because it does not sustain the balance of light absorption and utilization and consequently accumulates large amounts of $\mathrm{H}_{2} \mathrm{O}_{2}$ at PSII (Bascuñán-Godoy et al., 2018; Cisse et al., 2020). Diverse environmental stress can also result in the impairment of photosystem I (PSI) (Ivanov et al., 2015; Lima-Melo et al., 2019). The activity of PSI can be inhibited in Nicotiana tabacum grown under N stress (Yue et al., 2021). However, the mechanism of inhibition of PSII and PSI by N stress is not well-understood.

Plants are susceptible to photodamage under $\mathrm{N}$ stress; however, they can dissipate excessive energy through nonphotochemical quenching (NPQ) pathway, the xanthophyll cycle, and state transitions (Takahashi and Badger, 2011; Pinnola and Bassi, 2018). Photoprotection of diatoms are elevated through NPQ during N starvation (Liefer et al., 2018; Li Z. et al., 2021). Photosynthetic electron transport [linear electron flow (LEF) and cyclic electron flow (CEF)] in the thylakoid membrane is very important for photoprotection in plants grown under N stress (Shikanai, 2007; Yamamoto et al., 2021). CEF and LEF are essential for balancing the production ratio of ATP/NADPH and for protecting photosystems from impairment by over-reduction of chloroplast stroma (Lu et al., 2020). PSII photodamage is avoided in Phaseolus vulgaris and Camellia sinensis grown under $\mathrm{N}$ limitation through enhancing $\mathrm{CEF}$ (Antal et al., 2010; Lin et al., 2016). Plants also effectively dissipated over-excitation by the transition of LEF to CEF, which relieves the excitation pressure in photosystems and diminishes ROS generation (Tu et al., 2016; Podgórska et al., 2020). This was confirmed in Solanum lycopersicum grown under high temperature and high light treated with LEF inhibitor: 3-(3,4dichlorophenyl)-1,1-dimethyl urea (DCMU) and CEF inhibitor: methyl viologen (MV) (Lu et al., 2017). CEF (CEF-PSI) and moderate photoinhibition of PSII are two main protecting mechanisms of PSI photoinhibition (Zhang et al., 2014; Huang et al., 2016a). CEF-PSI alleviates the over-reduction of acceptor side of PSI and the generation of superoxide anion, and also protects PSI from photoinhibition (Huang et al., 2012a). This has also been confirmed by the results observed in $P$. vulgaris and C. sinensis grown under N stress (Antal et al., 2010; Lin et al., 2016). On the other hand, the excess electron flow from PSII causes photoinhibition of PSI (Scheller and Haldrup, 2005; Rochaix, 2011). When DCMU is used to block the electron transport from PSII to PSI, the photoinhibition of PSI would not be observed in chilled Solanum tuberosum, Cucumis sativus, and Spinacia oleracea (Sonoike, 1996). Photoinhibition of A. thaliana pgr5-mutant and Psychotria rubra by high light can be alleviated when the addition of DCMU restricts the electron flow from PSII to PSI (Suorsa et al., 2012; Huang et al., 2016b). PSI photoinhibition is mainly dependent on the electron flow from PSII to PSI. Thus, photosynthetic electron transport plays an important role in photoprotection in the $\mathrm{N}$-stress plants.

Panax notoginseng (Burkill) F. H. Chen (Sanqi in Chinese) is a typically shade-tolerant and $\mathrm{N}$-sensitive species from the family of Araliaceae (Yang et al., 2008; Chen J.W. et al., 2016; Ou et al., 2020; Zhang Q.H. et al., 2020; Zhang J.Y. et al., 2021). Excessive application of $\mathrm{N}$ fertilizer is a problem in $P$. notoginseng production (Ou et al., 2020). $\mathrm{N}$ application rate in conventional cultivation of $P$. notoginseng is $450 \mathrm{~kg} \mathrm{ha}^{-1}$ (Xia et al., 2016), which not only exceeded its demand (Ou et al., 2011) but also increased root decay and mortality rate; thus, $P$. notoginseng has been commonly believed to be the $\mathrm{N}$-sensitive species (Zheng et al., 2017; Wei et al., 2018; Zhang J.Y. et al., 2020). There is an elevation in leaf biomass and $\mathrm{Chl}$ content of $P$. notoginseng accompanying with the decrease of $P_{\mathrm{n}}$ under $\mathrm{HN}$ application (Li, 2017; Cun et al., 2020). In our previous work, it has been recorded that the photosynthetic performance was significantly suppressed in HN- and LN-grown P. notoginseng (Cun et al., 2020; Zhang J.Y. et al., 2020; Cun et al., 2021). P. notoginseng grown under LN condition reduces the photochemical efficiency of PSII through NPQ, xanthophyll cycle, antioxidant pathways, Chl degradation, and nitrate metabolism (Zhang J.Y. et al., 2020). Photosynthetic capacity is reduced in $P$. notoginseng grown under $\mathrm{HN}$ application mainly due to the inactivation of Rubisco (Cun et al., 2021). In addition, the activation of CEF cannot completely protect PSII donor side from damage in $P$. notoginseng under $\mathrm{HN}$, but can attenuate PSI photodamage (Cun et al., 2021). However, the mechanism of the PSI and PSII photoinhibition in the $\mathrm{N}$-sensitive species $P$. notoginseng under $\mathrm{N}$ stress is still not completely understood, and the role of electron transport of PSII and PSI in photoinhibition needs to be further investigated.

In the present study, the photosystem activity, photosynthetic rate, excitation energy distribution, electron transport, OJIP kinetic curve, antioxidant enzyme activity, and P700 dark reduction curves were examined in the $\mathrm{LN}, \mathrm{MN}$, and HN plants in the presence of DCMU and MV. The spraying of DCMU and MV would inhibit LEF and CEF, respectively. We hypothesized that (i) LEF-mediated damage to the PSII OEC is the main cause of PSII photoinhibition under LN condition; (ii) over-reduction of PSI acceptor side is the main cause of PSI photoinhibition under LN; and (iii) the activation of CEF might protect PSI from photodamage under LN. 


\section{MATERIALS AND METHODS}

\section{Plant Materials and Growth Conditions}

The experiment site was situated in the teaching and experimental farm of Yunnan Agricultural University in Kunming, China $\left(102^{\circ} 45^{\prime} \mathrm{E}, 25^{\circ} 08^{\prime} \mathrm{N}\right)$. The physical and chemical properties of the raw soils used in the present study were as follows. $\mathrm{pH} 6.84$, organic matter $3.18 \%$, total $\mathrm{N} 0.17 \%$, total phosphorus $0.23 \%$, total potassium $0.24 \%$, available potassium $127.32 \mathrm{mg} \mathrm{g}^{-1}$, and available phosphorus $11.04 \mathrm{mg} \mathrm{kg}^{-1}$. In January 2019, healthy 1 -year-old P. notoginseng seedlings (purchased from the Wenshan Miao Xiang $P$. notoginseng Industrial Co., Ltd., Wenshan, China) were sterilized by $50 \%$ chloroisobromine cyanuric acid 1,000-fold dilution for $10 \mathrm{~min}$ and transplanted in pots $(32 \mathrm{~cm} \times 19 \mathrm{~cm} \times 21 \mathrm{~cm})$ with each containing three rootstocks, 140 pots per treatment were arranged. Five independent experiments were conducted in an environmentally controlled house with irradiance of about $10 \%$ full sunlight. Based on the application of $225 \mathrm{~kg}$ of phosphorus $\left(\mathrm{P}_{2} \mathrm{O}_{5}\right)$ and $225 \mathrm{~kg}$ of potassium $\left(\mathrm{K}_{2} \mathrm{O}\right)$ per hectare in $P$. notoginseng production, three nitrogen levels, LN (without $\mathrm{N}$ addition), moderate nitrogen $\left(\mathrm{MN}, 225 \mathrm{~kg} \mathrm{ha}^{-1} \mathrm{~N}\right)$, and $\mathrm{HN}\left(450 \mathrm{~kg} \mathrm{ha}^{-1} \mathrm{~N}\right)$, were designed for the present study. Fertilizer was applied in four times a year, and $\mathrm{N}$ was supplied in April, May, July, and August, respectively, each year. In August 2020, photosynthetic parameters were measured in mature leaves grown under different $\mathrm{N}$ regimes.

\section{Steady-State Photosynthetic Gas Exchange Rate}

The steady-state gas exchange parameters were measured by the photosynthesis system (Li-6400, Li-COR, Lincoln, NE, United States). The blue light ratio of the instrument, leaf temperature, and $\mathrm{CO}_{2}$ in the chamber were maintained at $10 \%$, $25^{\circ} \mathrm{C}$, and $400 \mu \mathrm{mol} \mathrm{mol}{ }^{-1}$, respectively. Leaves were adapted under light (500 $\mu \mathrm{mol} \cdot$ photons $\cdot \mathrm{m}^{-2} \mathrm{~s}^{-1}$ ) for $10 \mathrm{~min}$ before measurement, and the automatic measurement was started after the data had stabilized. Subsequently, the steady-state photosynthetic gas exchange rate was recorded after exposure for 2-3 min to each light intensity $(500,300,200,150,100,80$, $70,60,50,40,30$, and $20 \mu \mathrm{mol} \cdot$ photons $\cdot \mathrm{m}^{-2} \mathrm{~s}^{-1}$; five replicates per treatment). According to the study of Webb et al. (1974), the relationship between $P_{\mathrm{n}}$ and photosynthetic photon flux density (PPFD) was fitted $(n=5), P_{\mathrm{n}}=P_{\max }-P_{\max } \mathrm{C}_{0} \mathrm{e}^{-\alpha \mathrm{PPFD} / \mathrm{Pmax}}$ (Bassman and Zwier, 1991).

\section{Photosystem I and Photosystem II Measurements}

Biophysical parameters were measured simultaneously by Dual PAM 100 (Heinz Walz GmbH, Effeltrich, Germany). To measure the light response of the steady-state PSI and PSII parameters at various light intensities, healthy matured leaves were illuminated at a saturating light of $172 \mu \mathrm{mol} \cdot$ photons $\cdot \mathrm{m}^{-2} \mathrm{~s}^{-1}$ for $20 \mathrm{~min}$. Subsequently, photosynthetic capacity was evaluated at $30 \mathrm{~s}$ intervals at PPFD of $501,330,214,172,94,36,18,10$, and $0 \mu \mathrm{mol} \cdot$ photons $\cdot \mathrm{m}^{-2} \mathrm{~s}^{-1}$. The maximum quantum yield of PSII, $F_{\mathrm{v}} / F_{\mathrm{m}}=\left(F_{\mathrm{m}}-F_{\mathrm{o}}\right) / F_{\mathrm{m}}$, was measured to monitor PSII activity. $F_{\mathrm{o}}$ and $F_{\mathrm{m}}$ are the minimum and maximum fluorescence measured after $2 \mathrm{~h}$ dark adaptation. On the other hand, the PSI photosynthetic parameters were evaluated by Dual PAM 100 based on P700 oxidation signal (Klughammer and Schreiber, 2008). The maximum photo-oxidation $\mathrm{P} 700^{+}\left(P_{\mathrm{m}}\right)$ was determined using a saturation pulse of far-red pre-irradiation light; the determination of $P_{\mathrm{m}}$ ' differs from $P_{\mathrm{m}}$, in that $P_{\mathrm{m}}$ was determined using actinic light rather than far-red light (Takagi et al., 2017). Additionally, treated leaves were illuminated at a saturating light of $172 \mu \mathrm{mol} \cdot$ photons $\cdot \mathrm{m}^{-2} \mathrm{~s}^{-1}$ for $20 \mathrm{~min}$ to measure the light energy allocation and electron transport parameters. The formulae of $\mathrm{Chl}$ fluorescence parameters were shown in Supplementary Table 1 (Krall and Edwards, 1992; Strasser and Srivastava, 1995; Yamori et al., 2011; Huang et al., 2012b) $(n=5)$.

\section{Chl a Fluorescence Measurement and OJIP Transient Analyses}

The Chl $a$ fluorescence was measured simultaneously by Dual PAM 100. The plants were kept in the dark for $2 \mathrm{~h}$ to achieve a dark-adapted state with open reaction centers (RCs). When leaf was illuminated by a high density of actinic light $\left(10,000 \mu \mathrm{mol} \cdot\right.$ photons $\left.\cdot \mathrm{m}^{-2} \mathrm{~s}^{-1}\right)$, the fast fluorescence kinetics was recorded from $10 \mu \mathrm{s}$ to $1 \mathrm{~s}$. $F_{\mathrm{O}}, F_{\mathrm{J}}, F_{\mathrm{I}}$, and $F_{\mathrm{P}}$ correspond to the relative fluorescence intensity at the time points of $20 \mu \mathrm{s}$, 2, 30, and $300 \mathrm{~ms}$, respectively. The point of time corresponding to $300 \mu \mathrm{s}$ on the OJIP kinetic curves was defined as the $\mathrm{K}$ characteristic points. The ratio of variable $F_{\mathrm{K}}$ to the amplitude $\left(F_{\mathrm{J}}-F_{\mathrm{O}}\right)$ was calculated as: $W_{\mathrm{K}}=\left(F_{\mathrm{K}}-F_{\mathrm{O}}\right) /\left(F_{\mathrm{J}}-F_{\mathrm{O}}\right)(\mathrm{Li} \mathrm{P}$. et al., 2009). The parameter $W_{K}$ is an indicator of damage to the OEC activity (Strasser, 1997; Strasser et al., 2000, 2004; De Ronde et al., 2004; Li P. et al., 2009). The parameter $P I_{\mathrm{ABS}}$ is a performance index (potential) for energy conservation from excitation to the reduction of intersystem electron acceptors (Strasser et al., 2000, 2004). For a detailed analysis of the whole fluorescence kinetics, different normalizations and kinetic differences in calculations were undertaken. Abbreviations, formulas, and definitions of the JIP-test parameters used in the present study were presented in Supplementary Table 1 (Strasser et al., 2000; Kumar et al., 2020; Devadasu et al., 2021) $(n=5)$.

\section{Measurement of Plastoquinone Pools}

The P700 signal was determined during single-turn saturation pulse [ST, $50 \mathrm{~ms}$, plastoquinone (PQ) pools being oxidized] followed by multiple-turn saturation pulse (MT, $50 \mathrm{~ms}$, PQ pools fully reduced) in the presence of far-red background light (Savitch et al., 2001; Luo et al., 2021). The complementary area between the P700 oxidation curve after a single-turnover and multiple-turnover excitations and the stationary level of $\mathrm{P}^{2} 00^{+}$ under far-red light represents the single-turn and multiple-turn areas, respectively. These were used to calculate the functional pool sizes of the intersystem electrons relative to P700 as: $\mathrm{e}^{-/ \text {P700 }}=$ multiple-turn areas/single-turn areas (Savitch et al., 2001) $(n=5)$. 

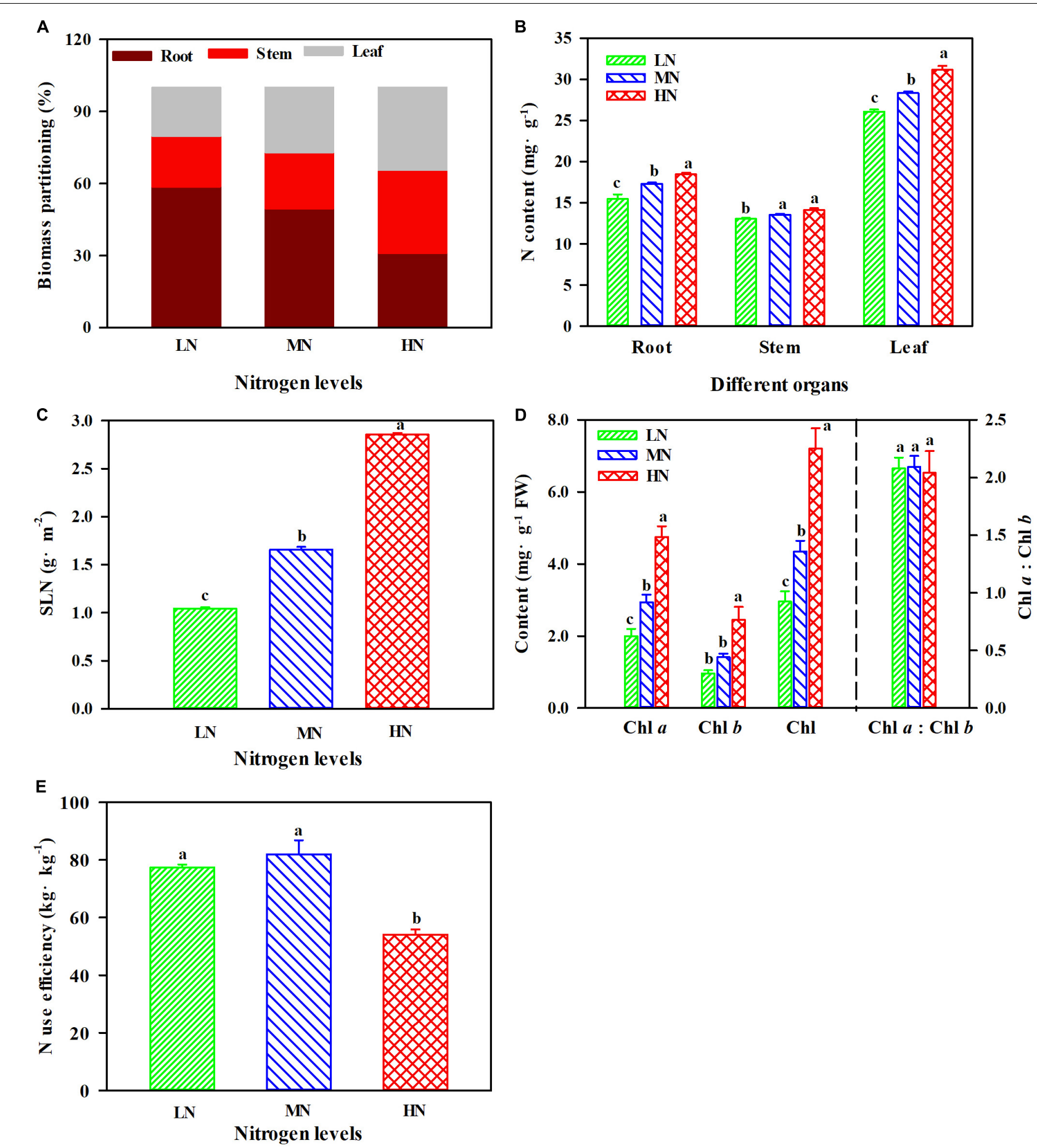

FIGURE 1 | The effect of nitrogen (N) regimes on biomass partitioning (A), $\mathrm{N}$ content (B), specific leaf $\mathrm{N}$ (SLN) (C), chlorophyll content (D), and $\mathrm{N}$ use efficiency (E) in Panax notoginseng. Values for each point were mean $\pm \mathrm{SD}(n=5)$. Different letters indicate significant differences among treatments (ANOVA; $p<0.05)$.

\section{Photoinhibitory Treatments}

To determine the roles of electron transport from PSII and PSI redox state in PSI photoinhibition in $P$. notoginseng grown under different $\mathrm{N}$ levels, leaves were sprayed with $\mathrm{H}_{2} \mathrm{O}, \mathrm{MV}$ and DCMU in darkness. The electron transport inhibitor concentration with the greatest inhibition of PSI and PSII activity was selected for the treatment of $P$. notoginseng leaves (Supplementary Figure 1). In August 2020, 3-year-old $P$. notoginseng leaves were sprayed with $\mathrm{H}_{2} \mathrm{O}$, DCMU $(180 \mu \mathrm{m})$, and MV $(150 \mu \mathrm{m})$ for $12 \mathrm{~h}$ in darkness. The treated leaves were allowed to be air-dried for $10 \mathrm{~min}$ to 
remove excess water, and then steady-state photosynthetic gas exchange rate, Chl fluorescence, and PQ pools were measured $(n=5)$.

\section{Determination of Biomass and N Content}

After completing photosynthetic measurement, the tagged plants were measured for biomass (they are the dry weight of root, stem, and leaves). The $\mathrm{N}$ content was determined by the Kjeldahl method (Stafilov et al., 2020). Specific leaf N (SLN, $\mathrm{g} \mathrm{m}^{-2}$ ) was calculated $(n=5)$. Based on the biomass and $\mathrm{N}$ content, the $\mathrm{N}$ use efficient (NUE) was calculated as: NUE $\left(\mathrm{kg} \mathrm{kg}^{-1}\right)=$ yield (underground dry weight)/plant $\mathrm{N}$ accumulation (Ning et al., 2012; Wu et al., 2016) $(n=5)$.

\section{Photosynthetic Pigment Analyses}

About $0.5 \mathrm{~g}$ fresh leaves extracted by $25 \mathrm{ml}$ extraction mixture [acetone and anhydrous alcohol were mixed (v/v 1:1)] were placed under dark condition for $24 \mathrm{~h}$. Absorbance were performed at wavelengths of 663 and $645 \mathrm{~nm}$, respectively. Then pigment contents were calculated according to the method of Pérez-Patricio et al. (2018) $(n=5)$.

\section{Leaf Rubisco Activity}

Rubisco activity was evaluated according to Parry et al. (1997). The extraction solution was prepared as follows: $50 \mathrm{mM}$ Tris$\mathrm{HCl}(\mathrm{pH} 8.0), 10 \mathrm{mM} \beta$-mercaptoethanol, $12.5 \%$ glycerol (v/v), $1 \mathrm{mM}$ ethylenediaminetetraacetic acid (EDTA)- $\mathrm{Na}_{2}, 10 \mathrm{mM}$ $\mathrm{MgCl}_{2}$ and $1 \%$ polyvinylpyrrolidone (PVP)-40 (m/v). Extracts were clarified by centrifugation $\left(8,000 \times g\right.$ at $4^{\circ} \mathrm{C}$ for $\left.10 \mathrm{~min}\right)$, and the supernatant was immediately assayed for Rubisco activity $(n=5)$.

\section{Determination of Antioxidant Enzyme Activity}

Determination of antioxidant enzyme activity was measured as described in Fatemi et al. (2021). After photoinhibitory treatments, the leaves were harvested and immediately frozen in liquid $\mathrm{N}$, and stored at $-80^{\circ} \mathrm{C}$. Leaves (ca. $0.1 \mathrm{~g}$ ) were crushed into a fine powder using a mortar and pestle under liquid N. Cell-free homogenates for antioxidant enzyme assays were prepared. Superoxide dismutase (SOD) activity was measured by the nitroblue tetrazolium (NBT) reduction method (Nebot et al., 1993). Glutathione peroxidase (POD) activity was measured by the guaiacol oxidation method (Polle et al., 1994; Shi et al., 2010). Catalase (CAT) activity was measured by the UV absorption method (Chen et al., 2011).

\section{Statistical Analysis}

All data obtained were analyzed with one-way ANOVA with statistical software (IBM SPSS 20.0, IBM Corp., Armonk, NY, United States). Means were separated by the Duncan's test, and $p$-values less than 0.05 were considered statistically significant, where the data were tested to confirm normality and the variables were present as the mean $\pm \mathrm{SD}(n=5)$. Subsequently, SigmaPlot 12.5 (Systat Software Inc., San Jose, CA, United States) and GraphPad Prism 8.0 (CA, United States) software were used to plot.

\section{RESULTS}

\section{Effect of N Regimes on Biomass Partitioning, N, and Chl Content}

There were significant differences in biomass allocation under $\mathrm{N}$ regimes. Leaf and stem biomass were greater when plants were exposed to HN compared with MN and LN, but the maximum value of root biomass was obtained in the LN plants (Figure 1A). $\mathrm{N}$ contents of different organs were significantly increased with the increase of $\mathrm{N}$ levels (Figure 1B), and the $\mathrm{N}$ content in leaves was significantly higher than that in roots and stems (Figure 1B; $p<0.05$ ). Additionally, SLN increased by $72.34 \%$ in $\mathrm{HN}$ plants compared with MN plants, and SLN declined by $40.00 \%$ in the LN plants (Figure 1C; $P<0.05$ ). The contents of Chl $a$, Chl $b$, and Chl were significantly increased with the increase of $\mathrm{N}$ levels, but the ratio of $\mathrm{Chl} a$ to $\mathrm{Chl} b$ (Chl $a$ : Chl $b$ ) was not significantly different among three treatments (Figure 1D). N use efficiency (NUE) did not show apparent differences between $\mathrm{LN}$ and MN plants, but the minimum values of NUE were generally recorded in the HN plants (Figure 1E; $p<0.05)$.

\section{Effect of N Regimes on Photosynthetic Rate, Photosystem, and Rubisco Activity}

The leaf exhibited a significant difference in response of $P_{\mathrm{n}}$ to incident PPFD within $\mathrm{N}$ regimes (Figure 2A). $P_{\mathrm{n}}$ were highest in MN-grown plants (Figure 2A). LN-grown leaves were dramatically reduced in activity of PSI $\left(P_{\mathrm{m}}\right.$, maximum photooxidation $\left.\mathrm{P} 700^{+}\right)$and PSII $\left(F_{\mathrm{v}} / F_{\mathrm{m}}\right.$, maximum photochemistry efficiency of PSII) (Figures 2B,C). $F_{\mathrm{v}} / F_{\mathrm{m}}$ did not show apparent difference between $\mathrm{MN}$ and $\mathrm{HN}$ plants (Figure 2B). Moreover, MN treatment exhibited 52.11-93.84\% more Rubisco activity than others (Figure 2D; $p<0.05$ ).

\section{Effects of \\ 3-(3,4-Dichlorophenyl)-1,1-Dimethyl Urea and Methyl Viologen on Photoinhibition of Photosystem I and Photosystem II Under N Regimes}

The $F_{\mathrm{v}} / F_{\mathrm{m}}$ and $P_{\mathrm{m}}$ decreased in samples were treated with DCMU and MV (Figure 3). Compared with the $\mathrm{H}_{2} \mathrm{O}$ treated plants, $F_{\mathrm{V}} / F_{\mathrm{m}}$ decreased by 4.8 and $12.5 \%$ in the DCMU- and MV-treated LN-grown plants (Figure 3A). In LN-grown plants treated with DCMU and $\mathrm{MV}$, the value of $P_{\mathrm{m}}$ reduced by 27.9 and $36.3 \%$, respectively (Figure 3B). In MN-grown plants treated with DCMU and $\mathrm{MV}$, the value of $F_{\mathrm{V}} / F_{\mathrm{m}}$ reduced by 11.0 and $8.5 \%$, respectively (Figure 3A). $P_{\mathrm{m}}$ decreased by 11.6 and $19.3 \%$ in the DCMU- and MV-treated MN-grown plants (Figure 3B). $F_{\mathrm{v}} / F_{\mathrm{m}}$ declined by 4.0 and $2.8 \%$ in $\mathrm{HN}$-grown plants treaded with DCMU and MV (Figure 3A). Meanwhile, $P_{\mathrm{m}}$ reduced by 21.4 and $30.1 \%$ in the DCMU- and MV-treated HN-grown plants (Figure 3B). 

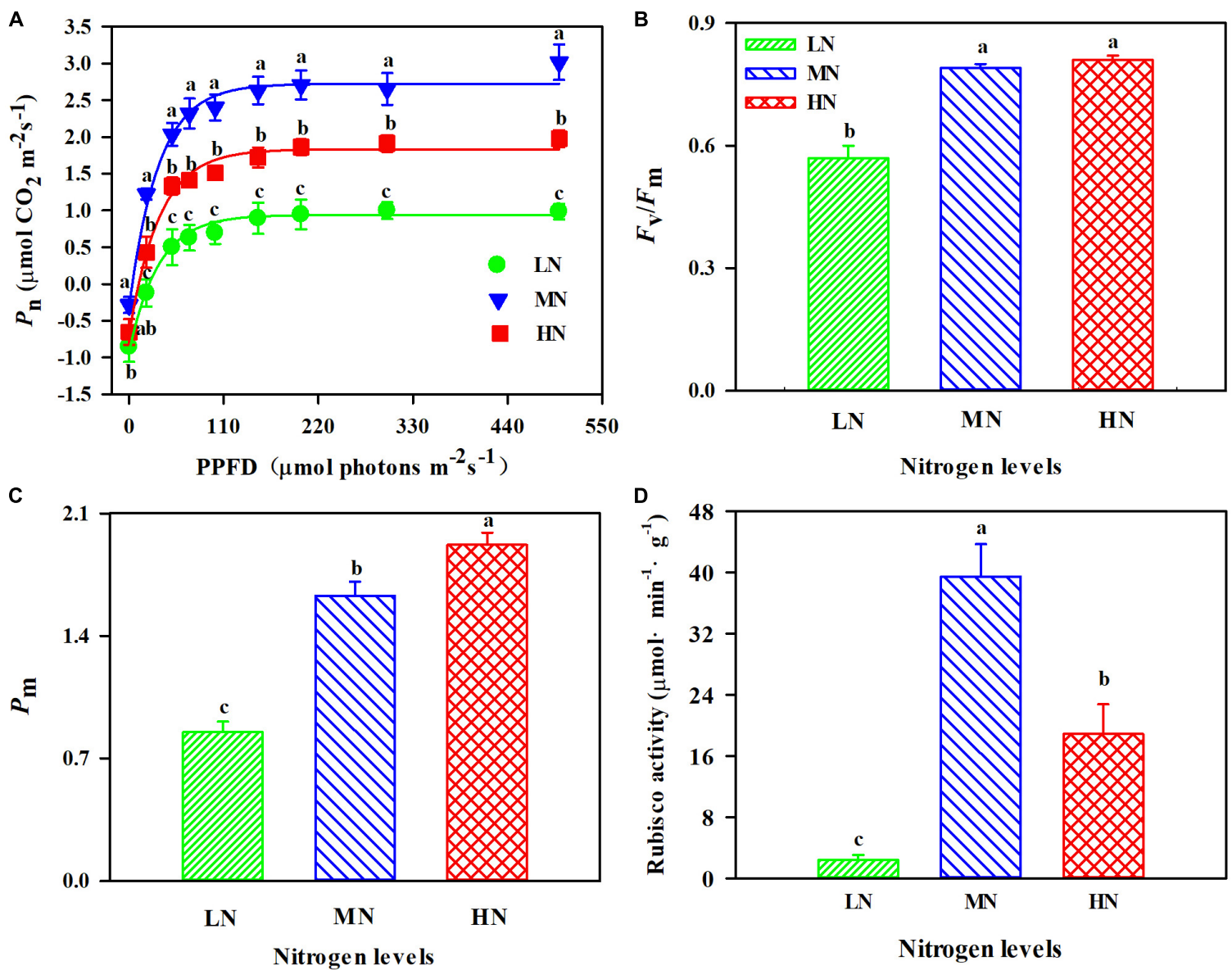

FIGURE 2 | (A) Response of net photosynthetic rate $\left(P_{n}\right)$ to photosynthetic photon flux density (PPFD) in Panax notoginseng grown under low nitrogen (LN, $0 \mathrm{~kg} \mathrm{hm}^{-2}$ ), moderate nitrogen (MN, $225 \mathrm{~kg} \mathrm{hm}^{-2}$ ), and high nitrogen ( $\mathrm{HN}, 450 \mathrm{~kg} \mathrm{hm}^{-2}$ ). The effects of nitrogen regimes on PSI (B), PSIl (C), and Rubisco activity (D) of $P$. notoginseng. $P_{\mathrm{m}}$ is the maximum photo-oxidation $\mathrm{P} 700^{+} ; F_{\mathrm{v}} / F_{\mathrm{m}}$ is the maximum efficiency of PSIl photochemistry. Values for each point were mean $\pm \mathrm{SD}$ $(n=5)$. Different letters among nitrogen regimes indicate significant difference $(p<0.05)$.
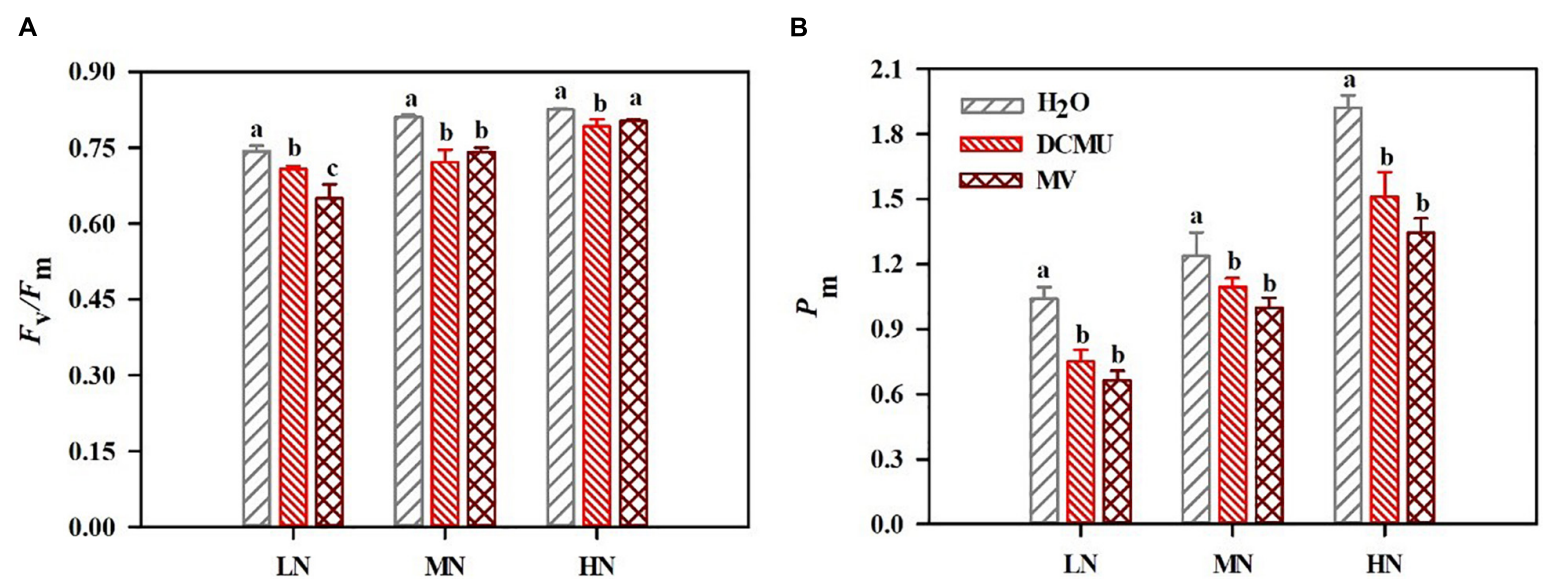

FIGURE 3 | Effects of 3-(3,4-dichlorophenyl)-1,1-dimethyl urea (DCMU) and methyl viologen (MV) on $F_{\mathrm{v}} / F_{\mathrm{m}}(\mathbf{A})$ and $P_{\mathrm{m}}$ (B) in leaves of $P$ anax notoginseng grown under different nitrogen regimes. After infiltration with chemical reagents $\left(\mathrm{H}_{2} \mathrm{O}, \mathrm{DCMU}\right.$, and $\left.\mathrm{MV}\right)$ in darkness for $12 \mathrm{~h}$. $F_{\mathrm{v}} / F_{\mathrm{m}}$, and $P_{\mathrm{m}}$ were measured as described in the section "Materials and Methods." Values for each point were mean \pm SD $(n=5)$. Different letters indicate significant differences among treatments $(p<0.05$, one-way ANOVA). 

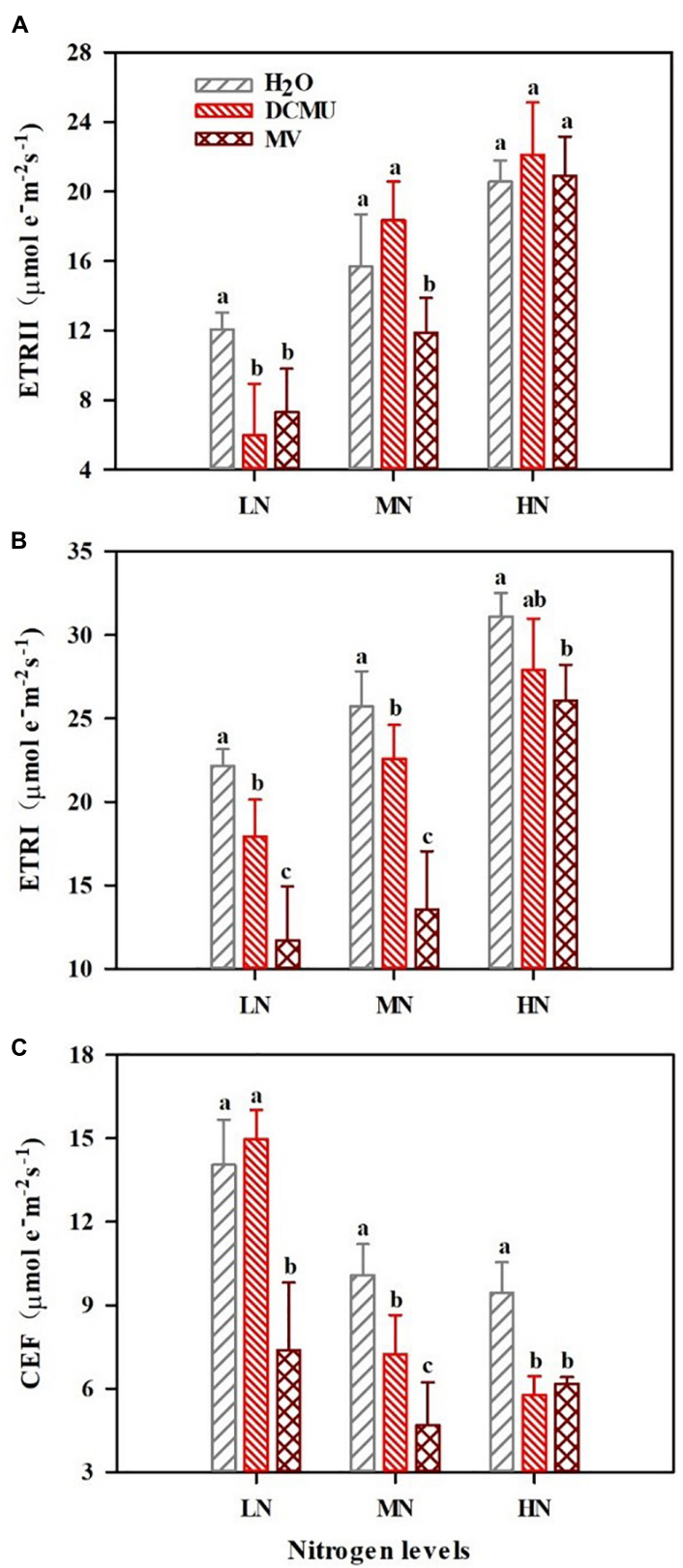

FIGURE 4 | Effects of 3-(3,4-dichlorophenyl)-1,1-dimethyl urea (DCMU) and methyl viologen (MV) on ETRII, ETRI, and cyclic electron flow (CEF) in leaves of Panax notoginseng grown under different nitrogen regimes. (A) ETRII is the electron transport rate of PSII. (B) ETRI is the electron transport rate of PSI. (C) $\mathrm{CEF}$ is the cyclic electron flow. Values for each point were mean $\pm \mathrm{SD}$ $(n=5)$. Different letters indicate significant differences among treatments $(p<0.05)$.

\section{3-(3,4-Dichlorophenyl)-1,1-Dimethyl Urea and Methyl Viologen Induce Changes in Photosynthetic Electron Transport Under N Regimes}

There were considerable differences in the photosynthetic electron transport under samples treated with DCMU and
MV (Figure 4; $p<0.05$ ). Electron transport rate of PSI (ETRI) and electron transport rate of PSII (ETRII) significantly reduced in LN-grown plants treated with DCMU (Figures 4A,B; $p<0.05)$. ETRI and CEF declined in MN-grown plants treated with DCMU (Figures 4B,C). In $\mathrm{MN}$ and $\mathrm{HN}$ plants treated with DCMU, the values of CEF decreased by 28.2 and $38.8 \%$, respectively (Figure 4C). Meanwhile, MV-treated plants showed lower levels of ETRI and ETRII under $\mathrm{N}$ regimes (Figures 4A,B). In $\mathrm{LN}, \mathrm{MN}$, and $\mathrm{HN}$ plants treated with $\mathrm{MV}$, the values of CEF reduced by $47.4,53.6$, and $34.6 \%$, respectively (Figure 4C).

\section{Responses of the OJIP Kinetic Curve to 3-(3,4-Dichlorophenyl)-1,1-Dimethyl Urea and Methyl Viologen Under N Regimes}

After spraying the electron transport inhibitor, the OJIP curve changes significantly (Figure 5; $p<0.05$ ). DCMU-treated samples showed higher $\mathrm{K}$ phase $(300 \mu \mathrm{s})$ and $\mathrm{J}$ phase $(2 \mathrm{~ms})$ in the OJIP kinetic curve than those treated with $\mathrm{H}_{2} \mathrm{O}$ and MV (Figure 5). Spraying of MV has no significant effect on the OJIP kinetic curve, but the minimum value of I phase (30 ms) appeared in MV-treated samples (Figure 5). IP phase was decreased in MV-treated $P$. notoginseng compared with $\mathrm{H}_{2} \mathrm{O}$-treated plants, and the minimum value of $\mathrm{P}$ phase $\left(F_{\mathrm{P}}\right)$ appeared in MV-treated samples (Figures 5, 6C). Further analysis of the JIP-test parameters showed that the photosynthetic characteristics of PSII were significantly affected after spraying the electron transport inhibitor (Figure 6; $p<0.05$ ). $P I_{\mathrm{ABS}}$ (performance index for energy conservation from photons absorbed by PSII antenna to the reduction of $\mathrm{Q}_{\mathrm{B}}$ ) and $V_{\mathrm{J}}$ (relative variable fluorescence at the J-step) decreased in LN- and HN-grown plants treated with DCMU and MV (Figures 6B,D), but $W_{\mathrm{K}}$ (the ratio of the variable fluorescent $F_{\mathrm{K}}$ occupying the $F_{\mathrm{J}}-F_{\mathrm{O}}$ amplitude) significantly increased in LN-grown plants treated with DCMU (Figure 6A; $p<0.05$ ). MN-grown plants treated with DCMU had significantly higher $V_{\mathrm{J}}$ and $W_{\mathrm{K}}$ (Figures 6A,B; $p<0.05$ ). Meanwhile, $P I_{\mathrm{ABS}}$ significantly declined in MN-grown plants treated with DCMU (Figure 6D; $p<0.05)$.

According to the above result, the $P I_{\mathrm{ABS}}$ and $W_{\mathrm{K}}$ correlated well with the $\mathrm{N}$ levels. To further assess the $\mathrm{N}$ tolerance of $P$. notoginseng, a model was developed based on the parameter $P I_{\mathrm{ABS}}$ and $W_{\mathrm{K}}$ (Figure 6E). The $P I_{\mathrm{ABS}}$ values decreased linearly as the K-step level $\left(W_{\mathrm{K}}\right)$ increased (Figure 6E). A significant negative linear correlation was observed between $P I_{\mathrm{ABS}}$ and $W_{\mathrm{K}}$ (Figure 6E). This linear relationship that the most important determinant of the PSII loss of function is the damage of OEC centers. The absolute value of the slope $(K)$ of the relationship between $P I_{\mathrm{ABS}}$ and $W_{\mathrm{K}}$ quantifies plant sensitivity to $\mathrm{N}$. The absolute value of the slope $(K)$ is $40.53(\mathrm{LN}), 48.23(\mathrm{MN})$, and $259.25(\mathrm{HN})$, respectively. It is clear that a lower absolute value of slope has a stronger tolerance to nitrogen. 

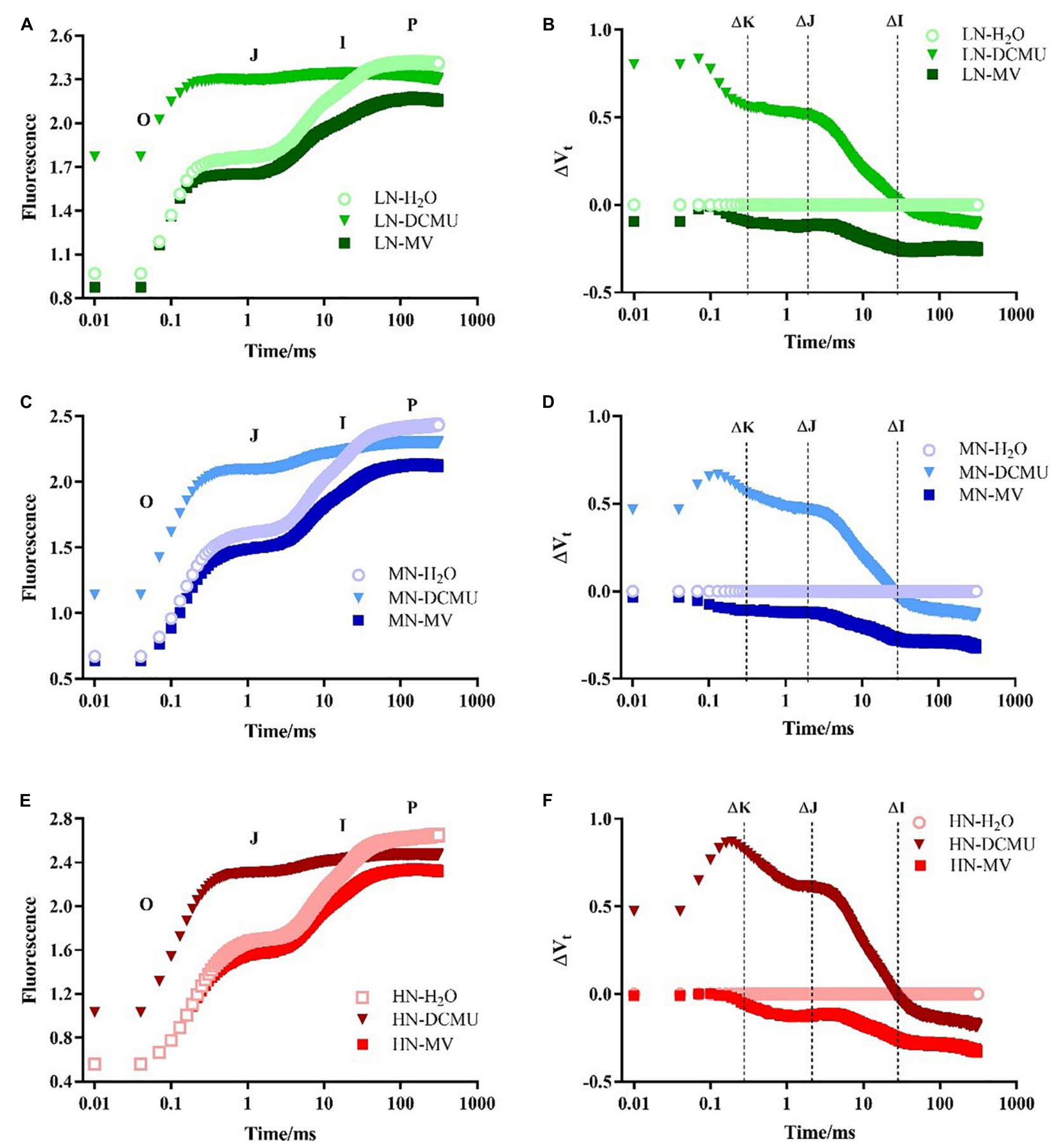

FIGURE 5 | Effects of 3-(3,4-dichlorophenyl)-1,1-dimethyl urea (DCMU) and methyl viologen (MV) on chlorophyll fluorescence transients in leaves of Panax notoginseng grown under different nitrogen $(\mathrm{N})$ regimes. After infiltration with chemical reagents $\left(\mathrm{H}_{2} \mathrm{O}, \mathrm{DCMU}\right.$, and MV) in darkness for $12 \mathrm{~h}$. OJIP kinetic curves were measured as described in the section "Materials and Methods." Panels (A,C,E) represent the N levels of LN, MN, and HN, respectively. O, J, I, and P phases represent the fluorescence at $T=20 \mu \mathrm{s}, 2,30$, and $300 \mathrm{~ms}$, respectively. Effect of $N$ levels $L N(B)$, MN (D), and $H N(\mathbf{F})$ on relative variable fluorescence $\left(\Delta V_{t}\right)$ of Panax notoginseng after infiltration with chemical reagents $\left(\mathrm{H}_{2} \mathrm{O}\right.$, DCMU, and $\left.\mathrm{MV}\right)$ in darkness. $\Delta \mathrm{V}_{\mathrm{t}}=\mathrm{V}$ (treatment) $-\mathrm{V}$ (control), $\mathrm{V}$ (treatment) is the fluorescence of $P$. notoginseng treated with $\mathrm{DCMU}$ or $\mathrm{MV}$; $\mathrm{V}$ (control) is the fluorescence of $P$. notoginseng treated with $\mathrm{H}_{2} \mathrm{O} . \Delta \mathrm{K}, \Delta \mathrm{J}$, and $\Delta \mathrm{I}$ represent the relative variable fluorescence at $\mathrm{T}=300 \mu \mathrm{s}, 2$, and $30 \mathrm{~ms}$, respectively. Values for each point were means $(n=5)$. 


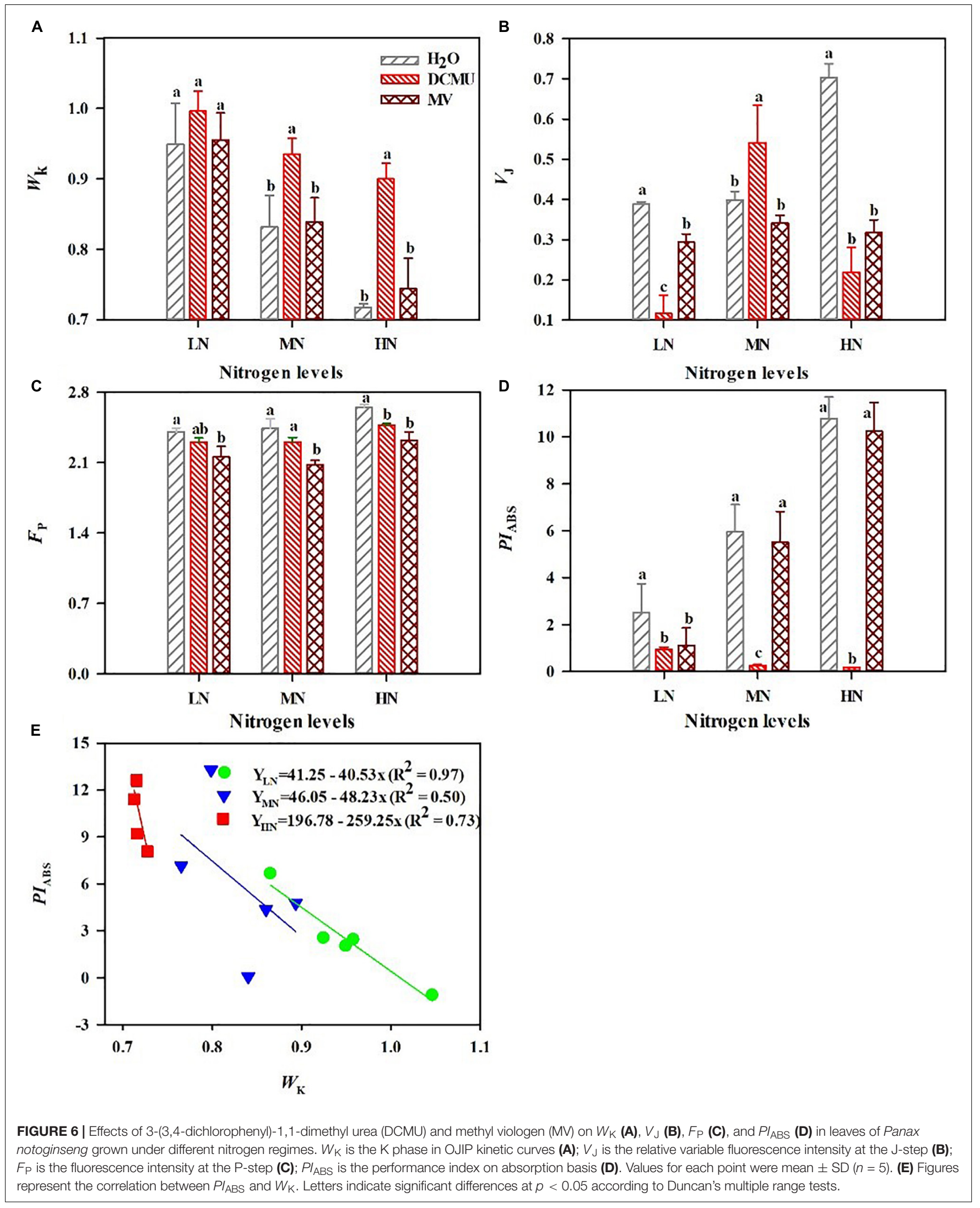




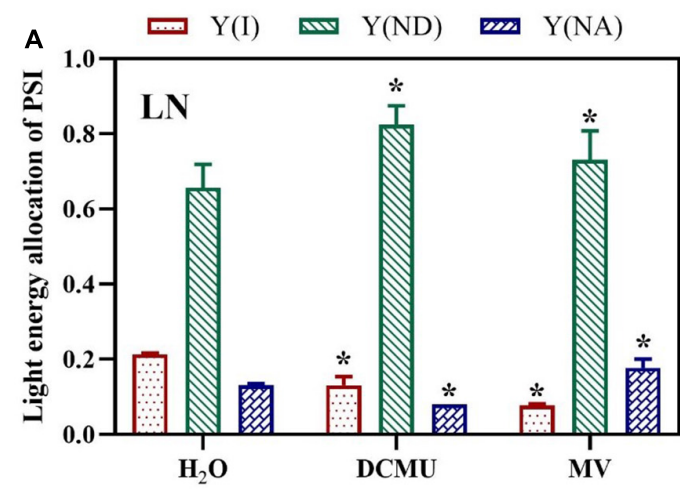

B

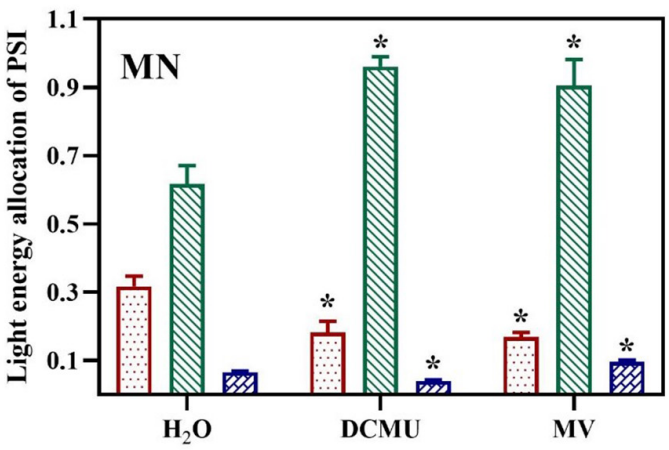

C

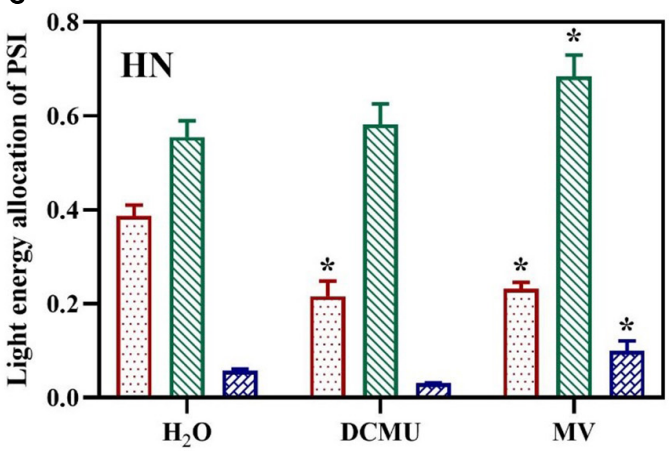

FIGURE 7 | Effects of 3-(3,4-dichlorophenyl)-1,1-dimethyl urea (DCMU) and methyl viologen (MV) on light energy allocation of PSI in Panax notoginseng grown under different nitrogen regimes (light adapted condition). Panels (A-C) represent the nitrogen $(\mathrm{N})$ levels of $\mathrm{LN}, \mathrm{MN}$, and $\mathrm{HN}$, respectively. $\mathrm{Y}(\mathrm{I})$ is the quantum yield of $\mathrm{PSI}$; $\mathrm{Y}(\mathrm{ND})$ is the donor side limitation of $\mathrm{PSI} ; \mathrm{Y}(\mathrm{NA})$ is the acceptor side limitation of PSI. Values for each point were means \pm SD $(n=5)$. Significant differences are indicated by asterisks (ANOVA; $p<0.05$ ). $\mathrm{LN}$, low N; MN, moderate N; HN, high N; MV, methyl viologen.

\section{Effects of 3-(3,4-Dichlorophenyl)-1,1-Dimethyl Urea and Methyl Viologen on the Distribution of Photosystem I Absorbed Light Energy in Panax notoginseng Leaves Under $\mathbf{N}$ Regimes}

Compared with the $\mathrm{H}_{2} \mathrm{O}$-treated leaves, values for $\mathrm{Y}(\mathrm{I}$ ) (quantum yield of PSI) in plants of leaves treated with DCMU and MV were decreased (Figure 7). Y(I) was lowest when the plant was exposed to LN, and the minimum value of $\mathrm{Y}(\mathrm{I})$ appeared in MVtreated plants (Figure 7A). The samples treated with DCMU and MV had significantly higher Y(ND) (donor side limitation of PSI) than the $\mathrm{H}_{2} \mathrm{O}$-treated samples (Figure 7; $p<0.05$ ). Meanwhile, MN-grown plants showed the highest levels of $\mathrm{Y}(\mathrm{ND})$ (Figure 7B). The value of Y(NA) (acceptor side limitation of PSI) was kept at low levels in samples treated with $\mathrm{H}_{2} \mathrm{O}$, DCMU, and MV, whereas the LN-grown plants showed higher $\mathrm{Y}(\mathrm{NA})$ (Figure 7). Concurrently, Y(NA) considerably enhanced in the MV-treated plants (Figure 7). Y(NA) was zero in the DCMU-treated plants (Figure 7).

\section{Response of the Redox Kinetics of P700 to 3-(3,4-Dichlorophenyl)-1,1-Dimethyl Urea and Methyl Viologen in N Regimes}

The P700 signal was determined during ST followed by MT in the presence of far-red background light and used ST areas/MT areas to characterize PQ pool size and the redox state (Savitch et al., 2001; Figure 8). In LN-, MN-, and HN-grown plants treated with DCMU, the PQ pool size increased by 60.3 , 22.3, and 59.5\%, respectively (Figure 8D). However, there were no significant differences in PQ pool size between $\mathrm{MV}$-treated and $\mathrm{H}_{2} \mathrm{O}$-treated plants (Figure 8D; $p>0.05$ ).

\section{Effects of}

\section{3-(3,4-Dichlorophenyl)-1,1-Dimethyl Urea and Methyl Viologen on Leaf Antioxidant Enzyme Activity Under N Regimes}

Activity of antioxidant enzymes in $P$. notoginseng showed significant differences between treatments (Figure 9; $p<0.05$ ). SOD and CAT activity substantially increased in LN- and MNgrown plants treated with MV (Figures 9A,C; $p<0.05$ ). Interestingly, SOD and CAT activity greatly reduced in $\mathrm{MN}$ and HN-grown plants treated with DCMU (Figures 9A,C; $p<0.05)$. All these MV-treated samples showed high levels of POD activity, and the highest activity was found in HN-grown plants (Figure 9B). Meanwhile, POD activity markedly declined in LN- and MN-grown plants treated with DCMU (Figure 9B; $p<0.05)$.

\section{DISCUSSION}

In this study, we examined the roles of electron transport in PSI and PSII photoinhibition in the $\mathrm{N}$-sensitive species $P$. notoginseng under $\mathrm{N}$ stress by treatments with diuron (DCMU) and MV. DCMU affects the primary photochemistry and blocks the electron transport from $\mathrm{Q}_{\mathrm{A}}$ to the secondary quinone acceptor $\mathrm{Q}_{\mathrm{B}}$ by interacting with D1 protein (Chen et al., 2007; Guo et al., 2020), whereas MV captures electrons from PSI ahead of FNR at almost the same rate as PSII is pumping them to PSI (Schansker et al., 2005). We found that PSI and PSII activities were considerably inhibited in LN plants as comparison with the other two treatments. Furthermore, LEF and CEF were an important determinant of PSI and PSII photoinhibition in 
A

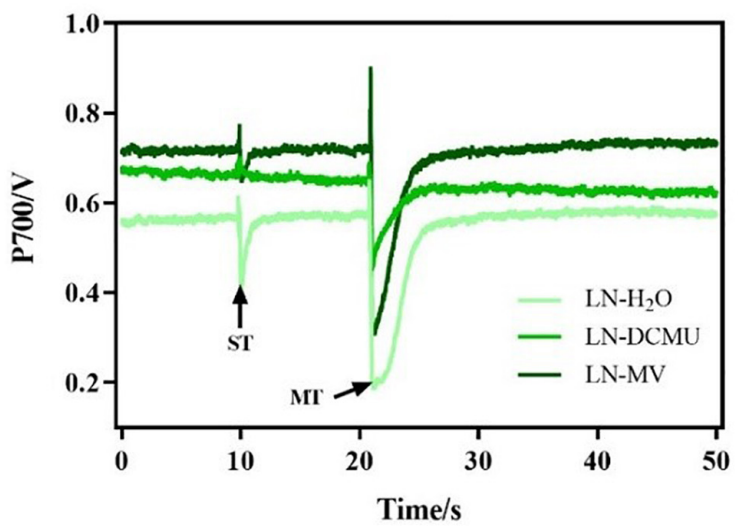

C

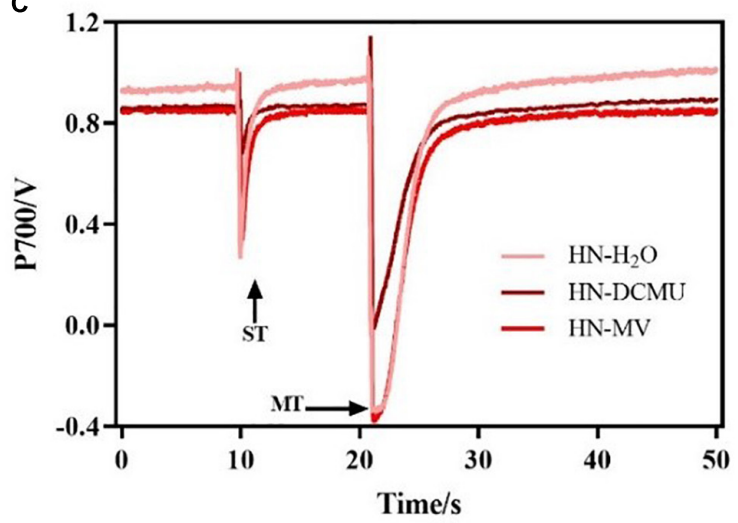

B

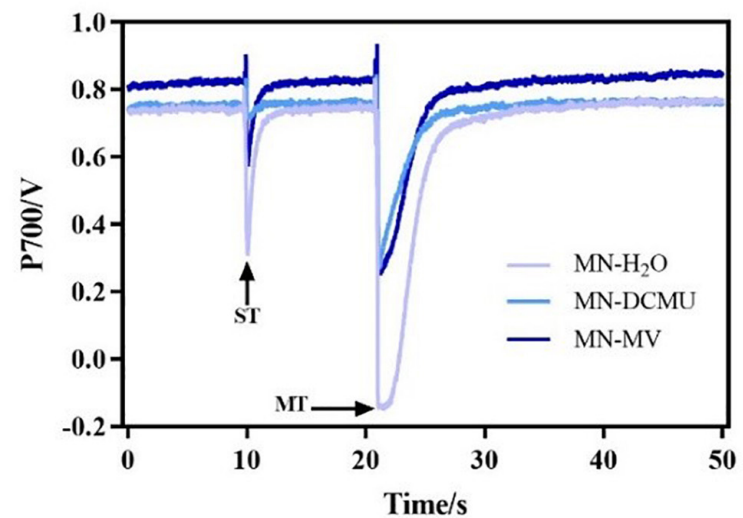

D

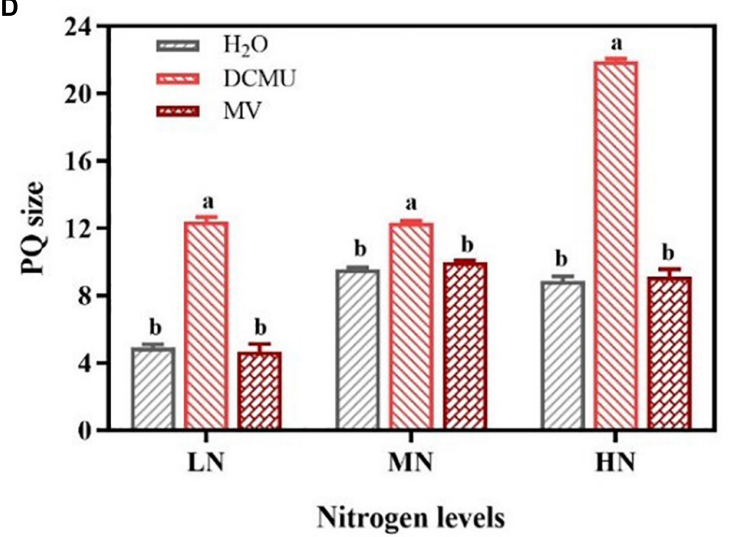

FIGURE 8 | Effects of 3-(3,4-dichlorophenyl)-1,1-dimethyl urea (DCMU) and methyl viologen (MV) on plastoquinone (PQ) in leaves of Panax notoginseng grown under different nitrogen regimes. Panels $(\mathbf{A}-\mathbf{C})$ represent the nitrogen $(\mathrm{N})$ levels of $L N, M N$, and $H N$, respectively. Panel (D) is the $P Q$ pool size. Values for each point were mean $\pm \mathrm{SD}(n=5)$. Letters indicate significant differences at $p<0.05$ according to Duncan's multiple range tests. ST, single-turn saturation pulse; MT, multi-turn saturation pulse; LN, low N; MN, moderate N; HN, high $\mathrm{N}$.

P. notoginseng grown under LN. Our present study has revealed some insights into the mechanism of $\mathrm{N}$ stress-induced PSII and PSI photoinhibition in an $\mathrm{N}$-sensitive species.

\section{Non-optimal N Regimes Inhibit Photosynthetic Capacity in an $\mathrm{N}$-Sensitive Species}

Nitrogen is one of the most important elements for plant photosynthesis as $\mathrm{N}$ is the main constituent of Rubisco, Chl, and photosynthetic proteins (Li et al., 2013; Mu and Chen, 2021). $\mathrm{N}$ uptake and utilization significantly affects photosynthetic efficiency (Evans and Clarke, 2019). Evidence shows that photosynthetic efficiency was increased with the increase of NUE in Platycodon grandiflorus and Abrus cantoniensis (Hu, 2006; Duan et al., 2015). However, root biomass and NUE increased in LN plants (Figure 1), whereas $P_{\mathrm{n}}, F_{\mathrm{v}} / F_{\mathrm{m}}$, and $P_{\mathrm{m}}$ declined (Figure 2). $P$. notoginseng promotes the accumulation of root biomass by increasing the NUE for survival under LN, but it does not contribute to photosynthesis. This has been confirmed by the performance observed in A. thaliana grown under $\mathrm{N}$ deficiency (Jia et al., 2020). Additionally, photosynthesis is closely related to leaf $\mathrm{N}$ and $\mathrm{Chl}$ contents (Rogers et al., 2017; Fraser, 2020). High SLN and Chl content induce the increase of light harvesting (Hikosaka, 2004). Our results are consistent with the previous studies that show SLN, Chl, $P_{\mathrm{n}}, F_{\mathrm{v}} / F_{\mathrm{m}}$, and $P_{\mathrm{m}}$ were reduced in Isatis indigotica and $P$. notoginseng under LN condition, thereby reducing light harvest and inhibiting photosynthesis (Guan et al., 2018; Figures 1, 2). Numerous studies have shown that the continued increase in SLN and Chl contents are detrimental to the balance of light harvesting and utilization, leading to a decrease in photosynthetic capacity (Li Y. et al., 2009; Moriwaki et al., 2019; Fraser, 2020). SLN, Chl, leaf, and stem biomass increased in HN plants, whereas $P_{\mathrm{n}}$ and NUE decreased (Figures 1, 2A), indicating photosynthetic efficiency was suppressed in $\mathrm{HN}$ condition. Meanwhile, the decrease in Rubisco and $P_{\mathrm{n}}$ has been observed in $P$. notoginseng grown under $\mathrm{HN}$ level (Figures 2A,D). The reduction in Rubisco activity and photosynthetic efficiency has been recorded in plants such as Malus domestica and Pseudotsuga menziesii var. menziesii (Cheng and Fuchigami, 2000; Manter et al., 2005). These results suggest that relatively less $\mathrm{N}$ operates on photosynthesis, when a high proportion of $\mathrm{N}$ served as $\mathrm{N}$ storage in HN-grown plants (Liu et al., 2018). Excessed SLN and Chl might cause 


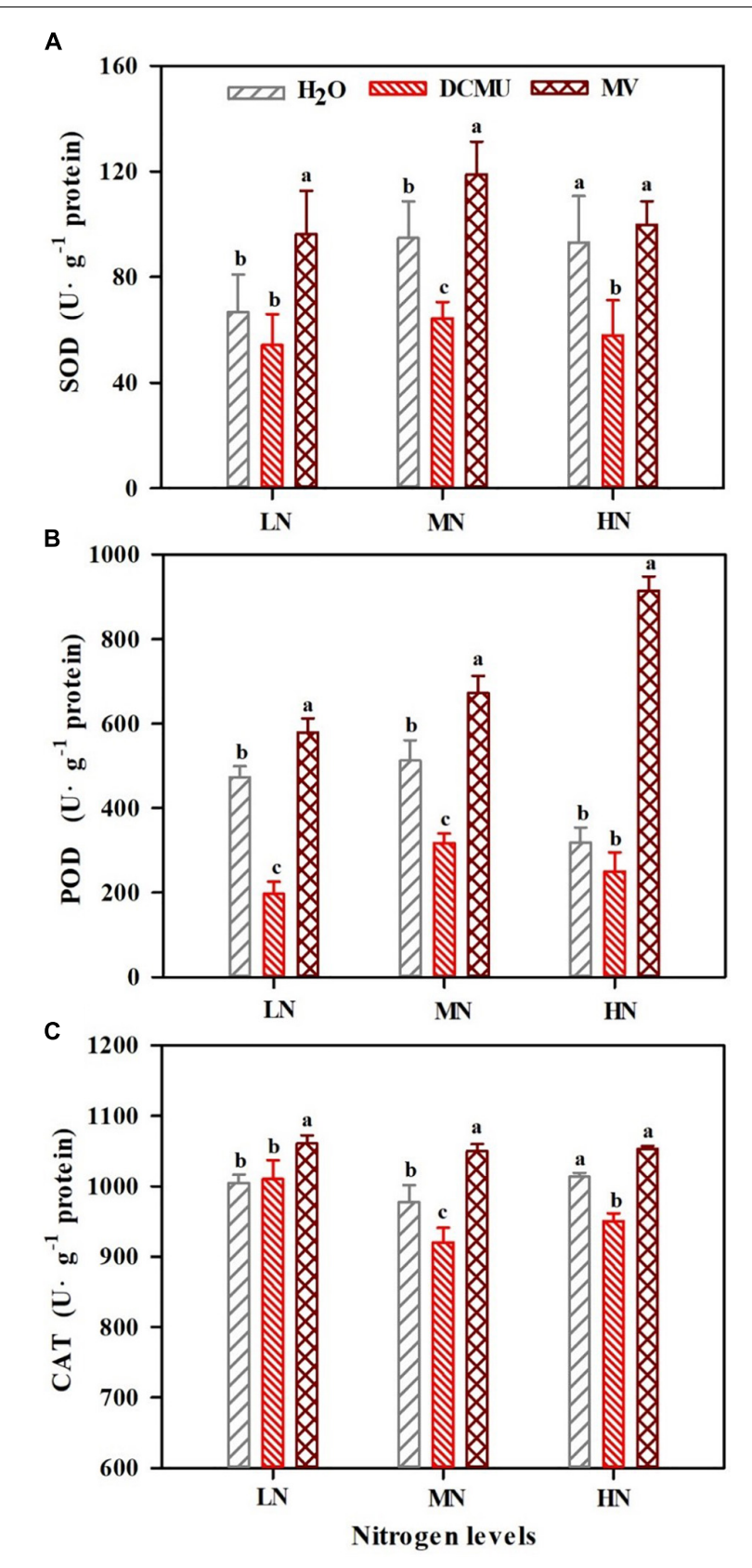

FIGURE 9 | Effects of 3-(3,4-dichlorophenyl)-1,1-dimethyl urea (DCMU) and methyl viologen (MV) on superoxide dismutase (SOD) (A), peroxidase (POD) (B), and catalase (CAT) (C) in leaves of Panax notoginseng grown under different nitrogen regimes. Values for each point were mean $\pm \mathrm{SD}(n=5)$. Letters indicate significant differences at $p \leq 0.05$ according to Duncan's multiple range tests. biomass and $\mathrm{N}$ content. However, the non-optimal SLN, Chl, and Rubisco activity in the $\mathrm{HN}$ and $\mathrm{LN}$ plants caused an imbalance between light energy capture and utilization, thereby inhibiting photosynthetic efficiency.

\section{Higher Cyclic Electron Flow Cannot Prevent Photosystem I and Photosystem II From Photoinhibition Under Low N Condition}

Photoinhibition of photosystems (PSI and PSII) occurs when the light energy absorbed by antenna pigment exceeds the capacity of photosynthetic apparatus (Sonoike, 2011; Tyystjärvi, 2013). $\mathrm{LEF}$ and $\mathrm{CEF}$ can rebalance ATP/NADPH and alleviate photoinhibition (Lu et al., 2020). $F_{\mathrm{V}} / F_{\mathrm{m}}$ and $P_{\mathrm{m}}$ were reduced by adding DCMU and MV that determine whether or not CEF and LEF are initiated (Figure 3). This has been confirmed by the performance observed in Fragaria ananassa, Lycopersicon esculentum, Dalbergia odorifera, Erythrophleum guineense, and P. rubra treated with DCMU and MV (Huang, 2012; Liu, 2015; Huang et al., 2016b; Lu, 2016). $F_{\mathrm{v}} / F_{\mathrm{m}}$ and $P_{\mathrm{m}}$ were significantly decreased in LN-grown plants treated with DCMU and MV (Figure 3). These results suggest that PSI and PSII are sensitive to LN, and MV and DCMU mainly inhibit the activities of PSI and PSII, respectively. On the other hand, it has been reported that Eupatorium adenophorum and Cerasus cerasoides adapt to the fluctuating light by enhancing electron transport to improve the utilization of light energy (Wang et al., 2004; Yang et al., 2019). ETRI, ETRII, and $F_{\mathrm{V}} / F_{\mathrm{m}}$ showed a decrease in LNgrown $P$. notoginseng (Figures 3A, 4A,B). We speculate that the reduction in PSII activity leads to the decrease in linear electron transport (ETRI and ETRII) when PSII photoinhibition occurs in LN-grown plants. The similar results have been recorded in P. notoginseng grown under low light and HN (Huang et al., 2018; Cun et al., 2021). In addition, CEF plays an important role in the adaptation of plants to environmental stress (Nawrocki et al., 2019; Sagun et al., 2019). The activation of CEF increases the adaptability of Tradescantia fluminensis leaves to high light stress (Kalmatskaya et al., 2020). CEF was higher in LN plants than in the $\mathrm{HN}$ and $\mathrm{MN}$ plants (Figure 4C). There were no significant differences in the CEF under $\mathrm{LN}$-grown plants treated with $\mathrm{H}_{2} \mathrm{O}$ and DCMU, but CEF, $F_{\mathrm{v}} / F_{\mathrm{m}}$, and $P_{\mathrm{m}}$ were significantly reduced in LN-grown plants treated with MV (Figures 3, 4C). Therefore, higher CEF cannot prevent PSI and PSII from photoinhibition under LN condition.

\section{Lower Linear Electron Transport Induces Photodamage to Photosystem II Donor Side Under Low N Condition}

The damage of PSII OEC and production of ROS are regarded as the two main causes of PSII photodamage (Li et al., 2018). The appearance of the $\mathrm{K}$ phase in OJIP is related to the damage of the PSII donor side, particularly the OEC (Strasser, 1997; Strasser et al., 2000, 2004; De Ronde et al., 2004; Li P. et al., 2009). The free radicals generated by excess excitation energy could damage the RC of PSII (excess-energy hypothesis; Krieger-Liszkay et al., 2008; Takahashi and Murata, 2008). $F_{\mathrm{v}} / F_{\mathrm{m}}$ was reduced in 


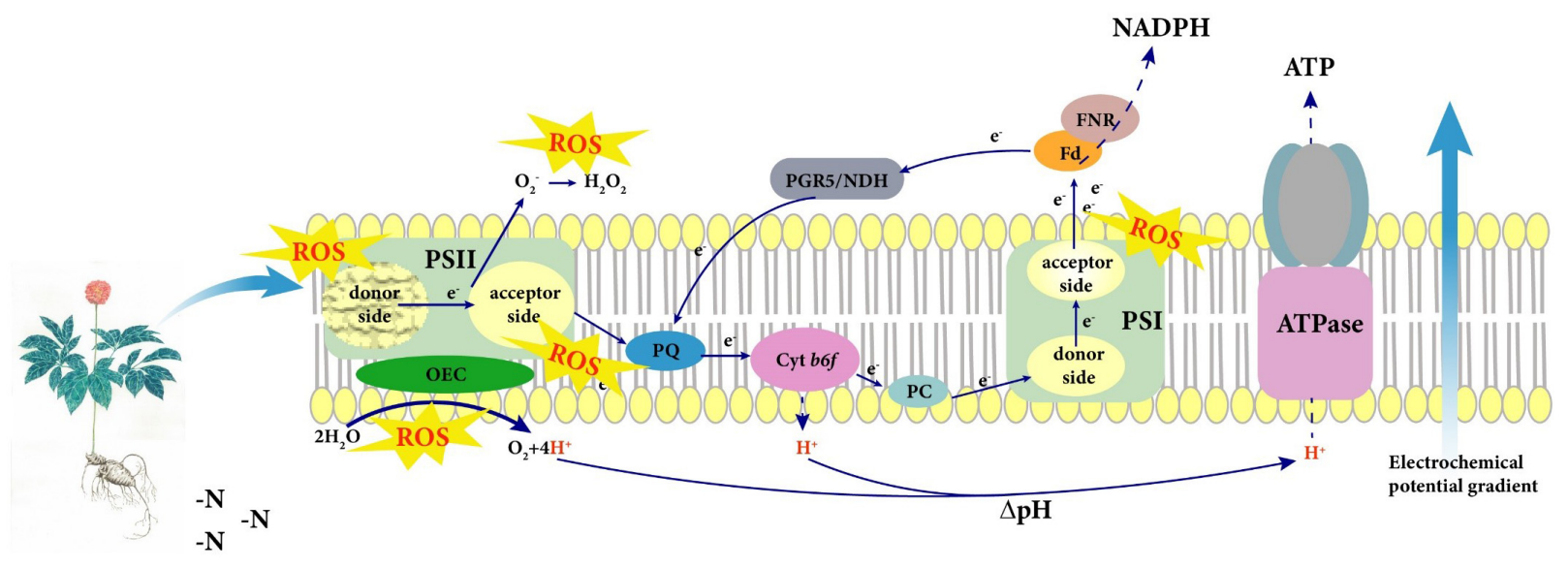

FIGURE 10 | A model was proposed for the adaptation strategy of photosystem in the nitrogen (N)-sensitive plants represented by Panax notoginseng under low $\mathrm{N}$ (LN) condition. The lower linear electron flow (LEF) leads to the hindrance of the formation of $\Delta \mathrm{pH}$ and ATP under LN, thereby damaging the donor side of the PSII oxygen-evolving complex (OEC). However, the activation of cyclic electron flow (CEF) slows down the damage rate of PSII under LN. Additionally, the over-reduction of PSI acceptor side is the main cause of PSI photoinhibition in N-sensitive species $P$. notoginseng under LN, and higher CEF and antioxidant enzyme activity protects PSI from photodamage. Craquelure represents the damage of photosystem.

P. notoginseng grown under LN (Figure 3A), and there was no significance in $W_{\mathrm{K}}$ in $\mathrm{LN}$-grown plants treated with $\mathrm{MV}$ and $\mathrm{H}_{2} \mathrm{O}$ (Figures 5, 6A). It indicates that additional free radicals cannot directly cause PSII photoinhibition in P. notoginseng under LN. Therefore, free radicals are not the main cause of photoinhibition of PSII under LN. Moreover, the photodamage of PSII occurs first at the OEC and then acts on the RC (Mn hypothesis; Murata et al., 2007; Nishiyama et al., 2011). $F_{\mathrm{V}} / F_{\mathrm{m}}$ and $P I_{\mathrm{ABS}}$ were decreased (Figures 3A, 6D), and $W_{\mathrm{K}}$ was increased in LN-grown plants treated with $\mathrm{H}_{2} \mathrm{O}, \mathrm{DCMU}$, and $\mathrm{MV}$ (Figure 6A). It might be speculated that LN-induced photoinhibition of PSII might be caused by the photodamage to the donor side of PSII OEC (Li P. et al., 2009). This has also been confirmed by the performance as has been observed in Vitis vinifera and Hordeum vulgare grown under drought stress (Christen et al., 2007; Oukarroum et al., 2007). A significant negative linear correlation was observed between $P I_{\mathrm{ABS}}$ and $W_{\mathrm{K}}$ (Figure 6E), this further confirms that the most important determinant of the PSII loss of function is the damage of OEC centers (Chen S. et al., 2016). Additionally, the most sensitive characteristic parameter $P I_{\mathrm{ABS}}$ and $W_{\mathrm{K}}$ of the OJIP kinetic curve is a useful and practical method for screening and assessing plant stress tolerance (Oukarroum et al., 2007; Boureima et al., 2012; Silvestre et al., 2014). This technique has successfully been applied to evaluate salinity sensitivity in Vigna radiata and Brassica juncea and heat tolerance in Ageratina adenophora (Misra et al., 2001; Chen S. et al., 2016). The absolute value of the slope $(K)$ is $40.53(\mathrm{LN}), 48.23(\mathrm{MN})$, and 259.25 $(\mathrm{HN})$, respectively (Figure 6E). It is clear that $P$. notoginseng is tolerant to $\mathrm{LN}$ and sensitive to $\mathrm{HN}$. This is consistent with our previous research results (Zhang J.Y. et al., 2020). Photodamage of PSII occurs when the rate of PSII photodamage is greater than the rate of PSII repairment (Miyata et al., 2015; Ueno et al., 2016; Takahashi et al., 2019). It has been reported that LEF facilitates the PSII repairment through a rapid formation of $\Delta \mathrm{pH}$ (the proton gradient across the thylakoid membranes) in A. thaliana and D. odorifera grown under high-light stress (Huang, 2012; Yamada et al., 2020). ETRI and ETRII decreased in LN plants (Figures 4A,B). These results indicate that lower LEF causes the formation of $\Delta \mathrm{pH}$ and ATP to be hindered, thereby inhibiting the repairment of PSII under LN. In other words, the inhibition of linear electron transport may cause damage to the OEC on the donor side of PSII under LN condition. $V_{\mathrm{J}}$ had the minimum value in LN plants treated with DCMU (Figures 5, 6B), and the DCMU-treated leaves still have the OJIP kinetics under MN and $\mathrm{HN}$ (Figures 5, 6B). The results imply that DCMU has inhibited all PSII RCs under LN condition, and the deactivation of PSII RC could produce a large number of free radicals (Domonkos et al., 2013; Tyystjärvi, 2013). However, the spraying of DCMU would weaken the inhibition of PSII RCs in $P$. notoginseng grown under $\mathrm{HN}$ and MN. The generation of ROS and the damage of OEC leads to PSII photodamage in $P$. notoginseng grown under LN. Overall, free radical production only inhibits PSII repairment and does not cause PSII damage, and lower LEF induces photodamage to PSII donor side under LN condition.

\section{Over-Reduction of Photosystem I Acceptor Side Under Low N Condition}

A reaction between reduced iron-sulfur centers and hydroxyl peroxide generates hydroxyl radicals that cause oxidative damage to PSI complexes (Sonoike, 2011). The over-reduction of PSI acceptor side and production of hydroxide at PSI acceptor side are regarded as two main causes of PSI photoinhibition (Munekage et al., 2002; Tikkanen et al., 2014). Water-water cycle induces the production of hydroxyl peroxide at PSI acceptor side in C. sativus, S. oleracea, A. thaliana, and S. lycopersicum under chilling temperature or high light, which further leads to PSI photoinhibition (Sonoike, 1996; Zhang and Scheller, 2004; Lu et al., 2017). Y(NA) decreased with the increase of $\mathrm{N}$ levels, but $\mathrm{Y}(\mathrm{ND})$ was significantly higher than $\mathrm{Y}(\mathrm{NA})$, and MV-treated 
plants showed higher Y(NA) (Figure 7). These results indicate that the donor side limitation-induced superoxide anions are generated at the PSI receptor side under $\mathrm{LN}$, which leads to excessive reduction of the PSI receptor side, thereby causing PSI photoinhibition. Moreover, it has been observed that the excitation of CEF might maintain the low reduction state of the PSI receptor side and the high oxidation state of P700 to prevent PSI from damage in P. vulgaris, Triticum aestivum, and C. sinensis grown under $\mathrm{N}$ deficient (Antal et al., 2010; Lin et al., 2016; Li H. et al., 2021). The size of PQ pool in LN plants was reduced, and the CEF was increased, and there were no significant differences in PQ pool size between MV-treated and $\mathrm{H}_{2} \mathrm{O}$-treated plants (Figures 4C, 8D). Therefore, the higher CEFinduced reduction in PQ pool not only reduces the acidification of the lumen, thereby preventing photodamage to PSI, but also slows the rate of damage to PSII OEC under LN, as has been confirmed in $P$. vulgaris and $C$ sinensis grown under $\mathrm{N}$ starvation (Antal et al., 2010; Lin et al., 2016). Nevertheless, higher PQ pool size was recorded in DCMU-treated plants. We speculate that lower CEF cannot alleviate the over-reduction of the PQ pool in DCMU-treated plants and thus inhibit the photosynthetic capacity (Figure 8D), as has been confirmed by Allen (2003). On the other hand, antioxidant enzymes (SOD, POD, CAT, etc.) play an important role in scavenging ROS (Foyer et al., 1994). It has been reported that MV significantly increases the activity of CAT and POD in Salvia miltiorrhiza, whereas DCMU inhibits the effects of MV (Xing et al., 2014). These are in line with results obtained in the present study that MV significantly enhanced the activity of SOD, CAT, and POD in P. notoginseng, whereas DCMU suppressed the activity of antioxidant enzyme (Figure 9). Enhanced antioxidant activity protects PSI from photodamage in $P$. notoginseng grown under LN. Therefore, over-reduction of PSI acceptor side is the main cause of PSI photoinhibition under LN condition, and higher CEF and activity of antioxidant enzyme protect PSI from photodamage.

\section{CONCLUSION}

Non-optimal $\mathrm{N}$ regimes significantly inhibit photosynthetic capacity of the $\mathrm{N}$-sensitive species such as $P$. notoginseng. Plants absorb $\mathrm{N}$ mainly for the accumulation of root biomass in LN condition. A high SLN and Chl might cause the imbalance between light capture and utilization, thus reducing photosynthetic carboxylation capacity in the HN plants. A model

\section{REFERENCES}

Allen, J. F. (2003). Cyclic, pseudocyclic and noncyclic photophosphorylation: new links in the chain. Trends Plant Sci. 8, 15-19. doi: 10.1016/s1360-1385(02) 00006-7

Antal, T., Mattila, H., Hakala-Yatkin, M., Tyystjärvi, T., and Tyystjärvi, E. (2010). Acclimation of photosynthesis to nitrogen deficiency in Phaseolus vulgaris. Planta 232, 887-898. doi: 10.1007/s00425-010-1227-5

Bascuñán-Godoy, L., Sanhueza, C., Hernández, C. E., Cifuentes, L., Pinto, K., Álvarez, R., et al. (2018). Nitrogen supply affects photosynthesis and photoprotective attributes during drought-induced senescence in Quinoa. Front. Plant Sci. 9:994. doi: 10.3389/fpls.2018.00994 was proposed for the adaptation strategy of photosystem in the $\mathrm{N}$-sensitive plants represented by $P$. notoginseng under LN condition (Figure 10). The lower LEF leads to the hindrance of the formation of $\Delta \mathrm{pH}$ and ATP in LN plants, thereby damaging the donor side of the PSII OEC. The overreduction of PSI acceptor side is the main cause of PSI photoinhibition under LN condition. Additionally, higher CEF and activity of antioxidant enzyme not only protected PSI from photodamage but also slowed down the damage rate of PSII in $P$. notoginseng grown under LN.

\section{DATA AVAILABILITY STATEMENT}

The original contributions presented in the study are included in the article/Supplementary Material, further inquiries can be directed to the corresponding author.

\section{AUTHOR CONTRIBUTIONS}

J-WC directed the whole process of the experiment and also made suggestions for the writing of the manuscript. ZC participated in the whole experiment, analyzed the relevant experimental data, and wrote the manuscript. H-MW, J-YZ, and S-PS measured the light absorption in photosystem I and chlorophyll fluorescence. $\mathrm{H}-\mathrm{MW}$ and $\mathrm{JH}$ participated in the determination of photosynthetic pigment content and steadystate gas exchange measurements. All authors contributed to the article and approved the submitted version.

\section{FUNDING}

This research was supported by the National Natural Science Foundation of China (32160248 and 81860676) and by the Major Special Science and Technology Project of Yunnan Province (202102AA310048).

\section{SUPPLEMENTARY MATERIAL}

The Supplementary Material for this article can be found online at: https://www.frontiersin.org/articles/10.3389/fpls.2022. 796931/full\#supplementary-material

Bassman, J. H., and Zwier, J. C. (1991). Gas exchange characteristics of Populus trichocarpa. Tree Physiol. 8, 145-159. doi: 10.1093/treephys/8.2.145

Berry, J. O., Yerramsetty, P., Zielinski, A. M., and Mure, C. M. (2013). Photosynthetic gene expression in higher plants. Photosynth. Res. 117, 91-120. doi: 10.1007/s11120-013-9880-8

Boureima, S., Oukarroum, A., Diouf, M., Cisse, N., and Damme, P. V. (2012). Screening for drought tolerance in mutant germplasm of sesame (Sesamum indicum) probing by chlorophyll a fluorescence. Environ. Exp. Bot. 81, 37-43. doi: 10.1016/j.envexpbot.2012.02.015

Che, Y. H., Wang, H. R., Zhang, B. N., Gao, S. X., Wang, Z. H., Wang, Y., et al. (2020). Elevated air temperature damage to photosynthetic apparatus alleviated by enhanced cyclic electron flow around photosystem I in tobacco 
leaves. Ecotoxicol. Environ. Saf. 204:111136. doi: 10.1016/j.ecoenv.2020.111 136

Chen, J. W., Kuang, S. B., Long, G. Q., Yang, S. C., Meng, Z. G., Li, L. G., et al. (2016). Photosynthesis, light energy partitioning, and photoprotection in the shade-demanding species Panax notoginseng under high and low level of growth irradiance. Funct. Plant Biol. 43, 479-491. doi: 10.1071/FP1 5283

Chen, S., Yang, J., Zhang, M., Strasser, R. J., and Sheng, Q. (2016). Classification and characteristics of heat tolerance in Ageratina adenophora populations using fast chlorophyll $a$ fluorescence rise O-J-I-P. Environ. Exp. Bot. 122, 126-140. doi: 10.1016/j.envexpbot.2015.09.011

Chen, L. S., and Cheng, L. (2003). Both xanthophyll cycle-dependent thermal dissipation and the antioxidant system are up-regulated in grape (Vitis labrusca L. cv. Concord) leaves in response to N limitation. J. Exp. Bot. 54, 2165-2175. doi: $10.1093 /$ jxb/erg220

Chen, S., Xu, X., Dai, X., Yang, C., and Qiang, S. (2007). Identification of tenuazonic acid as a novel type of natural photosystem II inhibitor binding in $\mathrm{Q}_{B}$-site of Chlamydomonas reinhardtii. Biochim. Biophys. Acta 1767, 306-318. doi: 10. 1016/j.bbabio.2007.02.007

Chen, X. Y., Li, W., and Lu, Q. T. (2011). The xanthophylls cycle and antioxidative defense system are enhanced in the wheat hybrid subjected to high light stress. J. Plant Physiol. 168, 1828-1836. doi: 10.1016/j.jplph.2011.0 5.019

Cheng, L., and Fuchigami, L. H. (2000). Rubisco activation state decreases with increasing nitrogen content in apple leaves. J. Exp. Bot. 51, 1687-1694. doi: 10.1093/jexbot/51.351.1687

Christen, D., Schönmann, S., Jermini, M., Strasser, R. J., and Défago, G. (2007). Characterization and early detection of grapevine (Vitis vinifera) stress responses to esca disease by in situ chlorophyll fluorescence and comparison with drought stress. Environ. Exp. Bot. 60, 504-514. doi: 10.1016/j.envexpbot. 2007.02.003

Cisse, A., Zhao, X., Fu, W., Kim, R. E. R., Chen, T., Tao, L., et al. (2020). Nonphotochemical quenching involved in the regulation of photosynthesis of rice leaves under high nitrogen conditions. Int. J. Mol. Sci. 21:2115. doi: 10.3390/ ijms21062115

Cun, Z., Zhang, J. Y., and Chen, J. W. (2020). Effects of nitrogen addition on growth, photosynthetic characteristics and saponin content in two-year-old Panax notoginseng. Chin. J. Ecol. 39, 1101-1111. doi: 10.13292/j.1000-4890. 202004.029

Cun, Z., Zhang, J. Y., Wu, H. M., Zhang, L., and Chen, J. W. (2021). High nitrogen inhibits photosynthetic performance in a shade-tolerant and $\mathrm{N}$-sensitive species Panax notoginseng. Photosynth. Res. 147, 283-300. doi: 10.1007/s11120-02100823-5

De Ronde, J. A., Cress, W. A., Krüger, G. H., Strasser, R. J., and Van Staden, J. (2004). Photosynthetic response of transgenic soybean plants, containing an Arabidopsis P5CR gene, during heat and drought stress. J. Plant Physiol. 161, 1211-1224. doi: 10.1016/j.jplph.2004.01.014

Devadasu, E., Pandey, J., Dhokne, K., and Subramanyam, R. (2021). Restoration of photosynthetic activity and supercomplexes from severe iron starvation in Chlamydomonas reinhardtii. Biochim. Biophys. Acta 862:148331. doi: 10.1016/j. bbabio.2020.148331

Domonkos, I., Kis, M., Gombos, Z., and Ughy, B. (2013). Carotenoids, versatile components of oxygenic photosynthesis. Prog. Lipid Res. 52, 539-561. doi: 10.1016/j.plipres.2013.07.001

Duan, Y. J., Wang, K. C., Niu, L. H., Li, K., and Su, Y. Y. (2015). Effect of different nitrogen forms and ratio on growth and active ingredient content of Platycodon grandiflorum. China J. Chin. Mater. Med. 40, 3754-3759.

Evans, J. R., and Clarke, V. C. (2019). The nitrogen cost of photosynthesis. J. Exp. Bot. 70, 7-15. doi: 10.1093/jxb/ery366

Fatemi, H., Pour, B. E., and Rizwan, M. (2021). Foliar application of silicon nanoparticles affected the growth, vitamin C, flavonoid, and antioxidant enzyme activities of coriander (Coriandrum sativum L.) plants grown in lead (Pb)-spiked soil. Environ. Sci. Pollut. Res. Int. 28, 1417-1425. doi: 10.1007/ s11356-020-10549-x

Foyer, C. H., Kunert, K. J., and Lelandais, M. (1994). Photooxida stress in plants. Physiol. Plant 92, 696-717.

Fraser, L. H. (2020). TRY-A plant trait database of databases. Glob. Chang. Biol. 26, 189-190. doi: 10.1111/gcb.14869
Guan, J. J., Wang, G., Chen, X., Zhang, M. R., and Tang, X. Q. (2018). Effects of nitrogen nutrition on the growth and active components of Isatis indigotica Fort. seedlings. Chin. J. Ecol. 37, 2331-2338. doi: 10.13292/j.1000-4890.201808. 030

Guo, Y., Lu, Y., Goltsev, V., Strasser, R. J., Kalaji, H. M., Wang, H., et al. (2020). Comparative effect of tenuazonic acid, diuron, bentazone, dibromothymoquinone and methyl viologen on the kinetics of Chl a fluorescence rise OJIP and the $\mathrm{MR}_{820}$ signal. Plant Physiol. Biochem. 156, 39-48. doi: 10.1016/j.plaphy.2020.08.044

Hikosaka, K. (2004). Interspecific difference in the photosynthesis-nitrogen relationship: patterns, physiological causes, and ecological importance. J. Plant Res. 117, 481-494. doi: 10.1007/s10265-004-0174-2

Hou, W., Tränkner, M., Lu, J., Yan, J., Huang, S., Ren, T., et al. (2019). Interactive effects of nitrogen and potassium on photosynthesis and photosynthetic nitrogen allocation of rice leaves. BMC Plant Biol. 19:302. doi: 10.1186/s12870019-1894-8

$\mathrm{Hu}$, Y. (2006). Effect of Different Nitrogen Levels on Growth and Effective Components of Abrus Cantoniensis. Ph.D thesis, Guangxi: Guangxi University.

Huang, W. (2012). The Significant Role of Cyclic Electron Flow in Plants' Adaptation to Environmental Stresses. Ph.D thesis, Beijing: University of Science and Technology of China.

Huang, W., Yang, Y. J., Hu, H., and Zhang, S. B. (2016a). Moderate photoinhibition of photosystem II protects photosystem I from photodamage at chilling stress in tobacco leaves. Front. Plant Sci. 7:182. doi: 10.3389/fpls.2016.00182

Huang, W., Yang, Y. J., Zhang, J. L., Hu, H., and Zhang, S. B. (2016b). PSI photoinhibition is more related to electron transfer from PSII to PSI rather than PSI redox state in Psychotria rubra. Photosynth. Res. 129, 85-92. doi: 10.1007/s11120-016-0275-5

Huang, W., Yang, Y. J., Zhang, S. B., and Liu, T. (2018). Cyclic Electron flow around photosystem I promotes ATP synthesis possibly helping the rapid repair of photodamaged photosystem II at low light. Front. Plant Sci. 9:239. doi: $10.3389 /$ fpls.2018.00239

Huang, W., Zhang, S. B., and Cao, K. F. (2012a). Physiological role of cyclic electron floe in higher plants. Plant Sci. J. 30, 100-106. doi: 10.3724/SP.J.1142.2012. 10100s

Huang, W., Yang, S. J., Zhang, S. B., Zhang, J. L., and Cao, K. F. (2012b). Cyclic electron flow plays an important role in photoprotection for the resurrection plant Paraboea rufescens under drought stress. Planta 235, 819-828. doi: 10. 1007/s00425-011-1544-3

Ivanov, A. G., Morgan-Kiss, R. M., Krol, M., Allakhverdiev, S. I., Zanev, Y., Sane, P. V., et al. (2015). Photoinhibition of photosystem I in a pea mutant with altered LHCII organization. J. Photochem. Photobiol. B 152, 335-346. doi: 10. 1016/j.jphotobiol.2015.08.018

Jia, Z., Giehl, R. F. H., and von Wirén, N. (2020). The root foraging response under low nitrogen depends on DWARF1-mediated brassinosteroid biosynthesis. Plant Physiol. 183, 998-1010. doi: 10.1104/pp.20.00440

Jiang, C. D., Gao, H. Y., Zou, Q., Jiang, G. M., and Li, L. H. (2006). Leaf orientation, photorespiration and xanthophyll cycle protect young soybean leaves against high irradiance in field. Environ. Exp. Bot. 55, 87-96. doi: 10.1016/j.envexpbot. 2004.10.003

Kalmatskaya, O. A., Trubitsin, B. V., Suslichenko, I. S., Karavaev, V. A., and Tikhonov, A. N. (2020). Electron transport in Tradescantia leaves acclimated to high and low light: thermoluminescence, PAM-fluorometry, and EPR studies. Photosynth. Res. 146, 123-141. doi: 10.1007/s11120-020-00767-2

Klughammer, C., and Schreiber, U. (2008). Saturation Pulse method for assessment of energy conversion in PS I. PAM Application Notes 1, 11-14.

Krall, J. P., and Edwards, G. E. (1992). Relationship between photosystem II activity and $\mathrm{CO}_{2}$ fixation in leaves. Plant Physiol. 86, 180-187. doi: 10.1111/j.1399-3054. 1992.tb01328.x

Krieger-Liszkay, A., Fufezan, C., and Trebst, A. (2008). Singlet oxygen production in photosystem II and related protection mechanism. Photosynth. Res. 98, 551-564. doi: 10.1007/s11120-008-9349-3

Kumar, D., Singh, H., Raj, S., and Soni, V. (2020). Chlorophyll $a$ fluorescence kinetics of mung bean (Vigna radiata L.) grown under artificial continuous light. Biochem. Biophys. Rep. 24:100813. doi: 10.1016/j.bbrep.2020.100813

Li, J. (2017). Research on Different Irrigation Amount, Organic Fertilizer and Shade on Increasing Quality and Yield of YUNAN PANAX Notoginseng. Ph.D thesis, Kunming: Kunming University of Science and Technology. 
Li, L., Aro, E. M., and Millar, A. H. (2018). Mechanisms of photodamage and protein turnover in photoinhibition. Trends Plant Sci. 23, 667-676. doi: 10. 1016/j.tplants.2018.05.004

Li, P., Cheng, L., Gao, H., Jiang, C., and Peng, T. (2009). Heterogeneous behavior of PSII in soybean (Glycine $\max$ ) leaves with identical PSII photochemistry efficiency under different high temperature treatments. J. Plant Physiol. 166, 1607-1615. doi: 10.1016/j.jplph.2009.04.013

Li, Y., Gao, Y., Xu, X., Shen, Q., and Guo, S. (2009). Light-saturated photosynthetic rate in high-nitrogen rice (Oryza sativa L.) leaves is related to chloroplastic $\mathrm{CO}_{2}$ concentration. J. Exp. Bot. 60, 2351-2360. doi: 10.1093/jxb/erp127

Li, Y., Ren, B., Ding, L., Shen, Q., Peng, S., and Guo, S. (2013). Does chloroplast size influence photosynthetic nitrogen use efficiency? PLoS One 8:e62036. doi: 10.1371/journal.pone.0062036

Li, Z., Lan, T., Zhang, J., Gao, K., Beardall, J., and Wu, Y. (2021). Nitrogen limitation decreases the repair capacity and enhances photoinhibition of photosystem II in a Diatom. Photochem. Photobiol. 97, 745-752. doi: 10.1111/ php. 13386

Li, H., Li, J., Zhang, X., Shi, T., Chai, X., Hou, P., et al. (2021). Mesophyll conductance, photoprotective process and optimal $\mathrm{N}$ partitioning are essential to the maintenance of photosynthesis at $\mathrm{N}$ deficient condition in a wheat yellow-green mutant (Triticum aestivum L.). J. Plant Physiol. 263:153469. doi: 10.1016/j.jplph.2021.153469

Liefer, J. D., Garg, A., Campbell, D. A., Irwin, A. J., and Finkel, Z. V. (2018). Nitrogen starvation induces distinct photosynthetic responses and recovery dynamics in diatoms and prasinophytes. PLoS One 13:e0195705. doi: 10.1371/ journal.pone.0195705

Lima-Melo, Y., Alencar, V. T. C. B., Lobo, A. K. M., Sousa, R. H. V., Tikkanen, M., Aro, E. M., et al. (2019). Photoinhibition of photosystem I provides oxidative protection during imbalanced photosynthetic electron transport in Arabidopsis thaliana. Front. Plant Sci. 10:916. doi: 10.3389/fpls.2019.00916

Lin, Z. H., Zhong, Q. S., Chen, C. S., Ruan, Q. C., Chen, Z. H., and You, X. M. (2016). Carbon dioxide assimilation and photosynthetic electron transport of tea leaves under nitrogen deficiency. Bot. Stud. 57:37. doi: 10.1186/s40529-0160152-8

Liu, J. (2015). Application effect of "crop spring" amino acid fertilizer in production of strawberry under plastic tunnel. Ph.D thesis, Nanjing: Nanjing Agricultural University.

Liu, T., Ren, T., White, P. J., Cong, R., and Lu, J. (2018). Storage nitrogen coordinates leaf expansion and photosynthetic capacity in winter oilseed rape. J. Exp. Bot. 69, 2995-3007. doi: 10.1093/jxb/ery134

Lu, J., Yin, Z., Lu, T., Yang, X., Wang, F., Qi, M., et al. (2020). Cyclic electron flow modulate the linear electron flow and reactive oxygen species in tomato leaves under high temperature. Plant Sci. 292:110387. doi: 10.1016/j.plantsci. 2019.110387

Lu, T. (2016). The Response Mechanisms of Photoinhibition and Photoprotection in Tomato (Solaunm lycopersicum L.) Leaves to Sub-High Temperature and High Light Intensity Stress. Ph.D thesis, Shengyang: Shengyang Agricultural University.

Lu, T., Shi, J. W., Sun, Z. P., Qi, M. F., Liu, Y. F., and Li, T. L. (2017). Response of linear and cyclic electron flux to moderate high temperature and high light stress in tomato. J. Zhejiang Univ. Sci. B 18, 635-648. doi: 10.1631/jzus. B1600286

Luo, Y., Xie, Y., He, D., Wang, W., and Yuan, S. (2021). Exogenous trehalose protects photosystem II by promoting cyclic electron flow under heat and drought stresses in winter wheat. Plant Biol. 23, 770-776. doi: 10.1111/plb. 13277

Makino, A., and Osmond, B. (1991). Effects of nitrogen nutrition on nitrogen partitioning between chloroplasts and mitochondria in pea and wheat. Plant Physiol. 96, 355-362. doi: 10.1104/pp.96.2.355

Manter, D. K., Kavanagh, K. L., and Rose, C. L. (2005). Growth response of Douglas-fir seedlings to nitrogen fertilization: importance of Rubisco activation state and respiration rates. Tree Physiol. 25, 1015-1021. doi: 10.1093/treephys/ 25.8.1015

Martin, W. F., Bryant, D. A., and Beatty, J. T. (2018). A physiological perspective on the origin and evolution of photosynthesis. FEMS Microbiol. Rev. 42, 205-231. doi: 10.1093/femsre/fux056

Misra, A. N., Srivastava, A., and Strasser, R. J. (2001). Utilization of fast chlorophyll $a$ fluorescence technique in assessing the salt/ion sensitivity of mung bean and Brassica seedlings. J. Plant Physiol. 158, 1173-1181. doi: 10.1078/s01761617(04)70144-3

Miyata, K., Ikeda, H., Nakaji, M., Kanel, D. R., and Terashima, I. (2015). Rate constants of PSII photoinhibition and its repair, and PSII fluorescence parameters in field plants in relation to their growth light environments. Plant Cell Physiol. 56, 1841-1854. doi: 10.1093/pcp/pcv107

Moriwaki, T., Falcioni, R., Tanaka, F. A. O., Cardoso, K. A. K., Souza, L. A., Benedito, E., et al. (2019). Nitrogen-improved photosynthesis quantum yield is driven by increased thylakoid density, enhancing green light absorption. Plant Sci. 278, 1-11. doi: 10.1016/j.plantsci.2018.10.012

$\mathrm{Mu}, \mathrm{X}$., and Chen, Y. (2021). The physiological response of photosynthesis to nitrogen deficiency. Plant Physiol. Biochem. 158, 76-82. doi: 10.1016/j.plaphy. 2020.11.019

Munekage, Y., Hojo, M., Meurer, J., Endo, T., Tasaka, M., and Shikanai, T. (2002). PGR5 is involved in cyclic electron flow around photosystem I and is essential for photoprotection in Arabidopsis. Cell 110, 361-371. doi: 10.1016/s00928674(02)00867-x

Murata, N., Takahashi, S., Nishiyama, Y., and Allakhverdiev, S. I. (2007). Photoinhibition of photosystem II under environmental stress. Biochim. Biophys. Acta 1767, 414-421. doi: 10.1016/j.bbabio.2006.11.019

Nawrocki, W. J., Bailleul, B., Picot, D., Cardol, P., Rappaport, F., Wollman, F. A., et al. (2019). The mechanism of cyclic electron flow. Biochim. Biophys. Acta Bioenerg. 1860, 433-438. doi: 10.1016/j.bbabio.2018.12.005

Nebot, C., Moutet, M., Huet, P., Xu, J. Z., Yadan, J. C., and Chaudiere, J. (1993). Spectrophotometric assay of superoxide dismutase activity based on the activated autoxidation of a tetracyclic catechol. Anal. Biochem. 214, 442-451. doi: 10.1006/abio.1993.1521

Ning, Y. W., Cao, B. G., Ma, H. B., Wang, J. D., Zhang, H., Xu, X. J., et al. (2012). Effects of nitrogen application rate on dry matter accumulation, nitrogen efficiency, and potassium and sodium uptake of sweet potato (Ipomoea batatas) in coastal north Jiangsu province. Chin. J. Eco Agric. 20, 982-987. doi: 10.3724/ SP.J.1011.2012.00982

Nishiyama, Y., Allakhverdiev, S. I., and Murata, N. (2011). Protein synthesis is the primary target of reactive oxygen species in the photoinhibition of photosystem II. Physiol. Plant 142, 35-46. doi: 10.1111/j.1399-3054.2011. 01457.x

Ou, X., Cui, X., Zhu, D., Guo, L., Liu, D., and Yang, Y. (2020). Lowering nitrogen and increasing potassium application level can improve the yield and quality of Panax notoginseng. Front. Plant Sci. 11:595095. doi: 10.3389/fpls.2020.595095

Ou, X., Jin, H., Guo, L., Yang, Y., Cui, X., Xiao, Y., et al. (2011). Status and prospective on nutritional physiology and fertilization of Panax notoginseng. China J. Chin. Mater. Med. 36, 2620-2624.

Oukarroum, A., Madidi, S. E., Schansker, G., and Strasser, R. J. (2007). Probing the responses of barley cultivars (Hordeum vulgare L.) by chlorophyll $a$ fluorescence OLKJIP under drought stress and re-watering. Environ. Exp. Bot. 60, 438-446. doi: 10.1016/j.envexpbot.2007.01.002

Parry, M., Andralojc, P. J., Parmar, S., Keys, A. J., Habash, D., Paul, M. J., et al. (1997). Regulation of Rubisco by inhibitors in the light. Plant Cell Environ. 20, 528-534. doi: 10.1046/j.1365-3040.1997.d01-85.x

Perchlik, M., and Tegeder, M. (2018). Leaf amino acid supply affects photosynthetic and plant nitrogen use efficiency under nitrogen stress. Plant Physiol. 78, 174-188. doi: 10.1104/pp.18.00597

Pérez-Patricio, M., Camas-Anzueto, J. L., Sanchez-Alegría, A., Aguilar-González, A., Gutiérrez-Miceli, F., Escobar-Gómez, E., et al. (2018). Optical method for estimating the chlorophyll contents in plant leaves. Sensors 18:650. doi: 10.3390/ s18020650

Pinnola, A., and Bassi, R. (2018). Molecular mechanisms involved in plant photoprotection. Biochem. Soc. Trans. 46, 467-482. doi: 10.1042/BST20170307

Podgórska, A., Mazur, R., Ostaszewska-Bugajska, M., Kryzheuskaya, K., Dziewit, K., Borysiuk, K., et al. (2020). Efficient photosynthetic functioning of Arabidopsis thaliana through electron dissipation in chloroplasts and electron export to mitochondria under ammonium nutrition. Front. Plant Sci. 11:103. doi: $10.3389 /$ fpls. 2020.00103

Polle, A., Otter, T., and Seifert, F. (1994). Apoplastic peroxidases and lignification in needles of Norway spruce (Picea abies L.). Plant Physiol. 106, 53-60. doi: 10.1104/pp.106.1.53

Rochaix, J. D. (2011). Regulation of photosynthetic electron transport. Biochim. Biophys. Acta 1807, 375-383. doi: 10.1016/j.bbabio.2010.11.010 
Rogers, A., Medlyn, B. E., Dukes, J. S., Bonan, G., von Caemmerer, S., Dietze, M. C., et al. (2017). A roadmap for improving the representation of photosynthesis in Earth system models. New Phytol. 213, 22-42. doi: 10.1111/nph.14283

Sagun, J. V., Badger, M. R., Chow, W. S., and Ghannoum, O. (2019). Cyclic electron flow and light partitioning between the two photosystems in leaves of plants with different functional types. Photosynth. Res. 142, 321-334. doi: 10.1007/s11120-019-00666-1

Savitch, L. V., Barker-Astrom, J., Ivanov, A. G., Hurry, V., Oquist, G., Huner, N. P., et al. (2001). Cold acclimation of Arabidopsis thaliana results in incomplete recovery of photosynthetic capacity, associated with an increased reduction of the chloroplast stroma. Planta 214, 295-303. doi: 10.1007/s004250100622

Schansker, G., Tóth, S. Z., and Strasser, R. J. (2005). Methylviologen and dibromothymoquinone treatments of pea leaves reveal the role of photosystem I in the Chl a fluorescence rise OJIP. Biochim. Biophys. Acta 1706, 250-261. doi: 10.1016/j.bbabio.2004.11.006

Scheller, H. V., and Haldrup, A. (2005). Photoinhibition of photosystem I. Planta 221, 5-8. doi: 10.1007/s00425-005-1507-7

Shi, J., Fu, X. Z., Peng, T., Huang, X. S., Fan, Q. J., and Liu, J. H. (2010). Spermine pretreatment confers dehydration tolerance of citrus in vitro plants via modulation of antioxidative capacity and stomatal response. Tree Physiol. 30, 914-922. doi: 10.1093/treephys/tpq030

Shikanai, T. (2007). Cyclic electron transport around photosystem I: genetic approaches. Annu. Rev. Plant Biol. 58, 199-217. doi: 10.1146/annurev.arplant. 58.091406.110525

Silvestre, S., Arajúo, S. S., Vaz Patto, M. C., and Marques da Silva, J. (2014). Performance index: an expeditious tool to screen for improved drought resistance in the Lathyrus genus. J. Integr. Plant Biol. 56, 610-621. doi: 10.1111/ jipb. 12186

Sonoike, K. (1996). Degradation of psaB gene product, the reaction center subunit of photosystem I, is caused during photoinhibition of photosystem I: possible involvement of active oxygen species. Plant Sci. 115, 157-164. doi: 10.1016/ 0168-9452(96)04341-5

Sonoike, K. (2011). Photoinhibition of photosystem I. Physiol. Plant. 142, 56-64. doi: 10.1111/j.1399-3054.2010.01437.x

Stafilov, T., Špirić, Z., Glad, M., Barandovski, L., Baèeva Andonovska, K., Šajn, R., et al. (2020). Study of nitrogen pollution in the republic of north macedonia by moss biomonitoring and Kjeldahl method. J. Environ. Sci. Health A Tox. Hazard. Subst. Environ. Eng. 55, 759-764. doi: 10.1080/10934529.2020.1738825

Strasser, B. J. (1997). Donor side capacity of photosystem II probed by chlorophyll a fluorescence transients. Photosynth. Res. 52, 147-155.

Strasser, R. J., and Srivastava, A. (1995). Polyphasic chlorophyll a fluorescence transient in plants and cyanobacteria. Petrochem. Photobiol. 61, 32-42. doi: 10.1111/j.1751-1097.1995.tb09240.x

Strasser, R. J., Srivastava, A., and Tsimilli-Michael, M. (2000). "The fluorescence transient as a tool to characterize andscreen photosynthetic samples," in Probing Photosynthesis: Mechanisms, Regulation and Adaptation, eds M. Yunus, U. Pathre, and P. Mohanty (London, UK: Taylor and Francis), 445-483.

Strasser, R. J., Tsimilli-Michael, M., and Srivastava, A. (2004). Analysis of the chlorophyll a fluorescence transient. Chl. Fluorescence 19, 321-362. doi: 10. 1007/978-1-4020-3218-9_12

Suorsa, M., Järvi, S., Grieco, M., Nurmi, M., Pietrzykowska, M., Rantala, M., et al. (2012). PROTON GRADIENT REGULATION5 is essential for proper acclimation of Arabidopsis photosystem I to naturally and artificially fluctuating light conditions. Plant Cell 4, 2934-2948. doi: 10.1105/tpc.112.097162

Takagi, D., Amako, K., Hashiguchi, M., Fukaki, H., Ishizaki, K., Goh, T., et al. (2017). Chloroplastic ATP synthase builds up a proton motive force preventing production of reactive oxygen species in photosystem I. Plant J. 91, 306-324. doi: 10.1111/tpj.13566

Takahashi, H., Kusama, Y., Li, X., Takaichi, S., and Nishiyama, Y. (2019). Overexpression of orange carotenoid protein protects the repair of PSII under strong light in Synechocystis sp. PCC 6803. Plant Cell Physiol. 60, 367-375. doi: $10.1093 / \mathrm{pcp} / \mathrm{pcy} 218$

Takahashi, S., and Badger, M. R. (2011). Photoprotection in plants: a new light on photosystem II damage. Trends Plant Sci. 16, 53-60. doi: 10.1016/j.tplants.2010. 10.001

Takahashi, S., and Murata, N. (2008). How do environmental stresses accelerate photoinhibition? Trends Plant Sci. 13, 178-182. doi: 10.1016/j.tplants.2008.01. 005
Tantray, A. Y., Bashir, S. S., and Ahmad, A. (2020). Low nitrogen stress regulates chlorophyll fluorescence in coordination with photosynthesis and Rubisco efficiency of rice. Physiol. Mol. Biol. Plants 26, 83-94. doi: 10.1007/s12298-01900721-0

Tikkanen, M., Mekala, N. R., and Aro, E. M. (2014). Photosystem II photoinhibition-repair cycle protects photosystem I from irreversible damage. Biochim. Biophys. Acta 1837, 210-215. doi: 10.1016/j.bbabio.2013.10.001

Tu, W., Li, Y., Liu, W., Wu, L., Xie, X., Zhang, Y., et al. (2016). Spring ephemerals adapt to extremely high light conditions via an unusual stabilization of photosystem II. Front. Plant Sci. 6:1189. doi: 10.3389/fpls.2015.01189

Tyystjärvi, E. (2013). Photoinhibition of photosystem II. Int. Rev. Cell Mol. Biol. 300, 243-303. doi: 10.1016/B978-0-12-405210-9.00007-2

Ueno, M., Sae-Tang, P., Kusama, Y., Hihara, Y., Matsuda, M., Hasunuma, T., et al. (2016). Moderate heat stress stimulates repair of photosystem II during photoinhibition in Synechocystis sp. PCC 6803. Plant Cell Physiol. 57, 24172426. doi: $10.1093 / \mathrm{pcp} / \mathrm{pcw} 153$

Wang, J. F., Feng, Y. L., and Liang, H. Z. (2004). Adaptation of Eupatorium adenophorum photosynthetic characteristics to light intensity. Chin. J. Appl. Ecol. 15, 1373-1377. doi: 10.1088/1009-0630/6/5/011

Webb, W. L., Newton, M., and Starr, D. (1974). Carbon dioxide exchange of Alnus rubra. A mathematical model. Oecologia 17, 281-291. doi: 10.1007/BF00345747

Wei, W., Yang, M., Liu, Y., Huang, H., Ye, C., Zheng, J., et al. (2018). Fertilizer N application rate impacts plant-soil feedback in a sanqi production system. Sci. Total Environ. 2018, 796-807. doi: 10.1016/j.scitotenv.2018.03.219

Wu, C. H., Liu, Q., Kong, F. M., Li, H., and Shi, Y. X. (2016). Effects of nitrogen application rates on root yield and nitrogen utilization in different purple sweetpotato varieties. Acta Agron. Sin. 42, 113-122. doi: 10.3724/SP.J.1006. 2016.00113

Xia, P., Guo, H., Zhao, H., Jiao, J., Deyholos, M. K., Yan, X., et al. (2016). Optimal fertilizer application for Panax notoginseng and effect of soil water on root rot disease and saponin contents. J. Ginseng. Res. 40, 38-46. doi: 10.1016/j.jgr.2015. 04.003

Xing, B. Y., Zhu, N., Zhang, H. P., Yang, X. L., and Dong, J. E. (2014). Effects of methyl viologen on the antioxidant system in the cultured Salvia miltiorrhiza cells. Chin. J. Plant Ecol. 38, 507-514. doi: 10.3724/SP.J.1258.2014.00047

Yamada, S., Ozaki, H., and Noguchi, K. (2020). The mitochondrial respiratory chain maintains the photosynthetic electron flow in Arabidopsis thaliana leaves under high-light stress. Plant Cell Physiol. 61, 283-295. doi: 10.1093/pcp/ pcz193

Yamamoto, C., Toyoshima, M., Kitamura, S., Ueno, Y., Akimoto, S., Toya, Y., et al. (2021). Estimation of linear and cyclic electron flows in photosynthesis based on 13C-metabolic flux analysis. J. Biosci. Bioeng. 131, 277-282. doi: 10.1016/j. jbiosc.2020.11.002

Yamori, W., Makino, A., and Shikanai, T. (2016). A physiological role of cyclic electron transport around photosystem I in sustaining photosynthesis under fluctuating light in rice. Sci. Rep. 6:20147. doi: 10.1038/srep2 0147

Yamori, W., Sakata, N., Suzuki, Y., Shikanai, T., and Makino, A. (2011). Cyclic electron flow around photosystem I via chloroplast $\mathrm{NAD}(\mathrm{P}) \mathrm{H}$ dehydrogenase (NDH) complex performs a significant physiological role during photosynthesis and plant growth at low temperature in rice. Plant J. 68, 966-976. doi: 10.1111/j.1365-313X.2011.04747.x

Yang, Y. J., Cui, X. M., Yang, T., and Xiao, F. H. (2008). Good Agricultural practice and developmental strategy for Panax notoginseng cultivation in Wenshan. J. Yunnan Agric. Univ. 23, 402-406. doi: 10.3724/SP.J.1005.2008. 01083

Yang, Y. J., Zhang, S. B., Wang, J. H., and Huang, W. (2019). Photosynthetic regulation under fluctuating light in field-grown Cerasus cerasoides: a comparison of young and mature leaves. Biochim. Biophys. Acta Bioenerg. 1860:148073. doi: 10.1016/j.bbabio.2019.148073

Yue, W., Jiechen, W., Huihui, Z., Dandan, G., Guoqiang, H., and Guangyu, S. (2021). A intermediate concentration of atmospheric nitrogen dioxide enhances PSII activity and inhibits PSI activity in expanded leaves of tobacco seedlings. Ecotoxicol. Environ. Saf. 209:111844. doi: 10.1016/j.ecoenv.2020. 111844

Zhang, G., Liu, Y., Ni, Y., Meng, Z., Lu, T., and Li, T. (2014). Exogenous calcium alleviates low night temperature stress on the photosynthetic apparatus of tomato leaves. PLoS One. 9:e97322. doi: 10.1371/journal.pone.0097322 
Zhang, Q. H., Zhang, J. Y., Cun, Z., and Chen, J. W. (2020). Effect of light and temperature on photosystem activities of Panax notoginseng. Acta Phytophysiol. Sin. 56, 1064-1072. doi: 10.13592/j.cnki.ppj.2019.0475

Zhang, J. Y., Cun, Z., and Chen, J. W. (2020). Photosynthetic performance and photosynthesis-related gene expression coordinated in a shade-tolerant species Panax notoginseng under nitrogen regimes. BMC Plant Biol. 20:273. doi: 10. 1186/s12870-020-02434-Z

Zhang, S., and Scheller, H. V. (2004). Photoinhibition of photosystem I at chilling temperature and subsequent recovery in Arabidopsis thaliana. Plant Cell Physiol. 45, 1595-1602. doi: 10.1093/pcp/pch180

Zhang, Z., Cao, B., Chen, Z., and Xu, K. (2021). Grafting enhances the photosynthesis and nitrogen absorption of tomato plants under low-nitrogen stress. J. Plant Growth Regul. [preprint]. doi: 10.1007/s00344-021-10414-2

Zhang, J. Y., Xu, X. Z., Kuang, S. B., Cun, Z., Wu, H. M., Shaung, S. P., et al. (2021). Constitutive activation of genes involved in triterpene saponins enhances the accumulation of saponins in three-year-old Panax notoginseng growing under moderate light intensity. Ind. Crops Prod. 171:113938. doi: 10.1016/j.indcrop. 2021.113938

Zhao, L. S., Li, K., Wang, Q. M., Song, X. Y., Su, H. N., Xie, B. B., et al. (2017). Nitrogen starvation impacts the photosynthetic performance of Porphyridium cruentum as revealed by chlorophyll $a$ fluorescence. Sci. Rep. 7:8542. doi: 10 . 1038/s41598-017-08428-6
Zheng, J. F., Yin, Z. B., Zhao, Z., Mao, Z. S., Wei, W., Wei, F. G., et al. (2017). Role of nitrogen and phosphorus fertilizer on seedling production of Panax notoginseng. J. Yunnan Agric. Univ. 32, 113-119. doi: 10.16211/j.issn.1004390X(n).2017.01.017

Conflict of Interest: The authors declare that the research was conducted in the absence of any commercial or financial relationships that could be construed as a potential conflict of interest.

Publisher's Note: All claims expressed in this article are solely those of the authors and do not necessarily represent those of their affiliated organizations, or those of the publisher, the editors and the reviewers. Any product that may be evaluated in this article, or claim that may be made by its manufacturer, is not guaranteed or endorsed by the publisher.

Copyright (C) 2022 Cun, Wu, Zhang, Shuang, Hong and Chen. This is an openaccess article distributed under the terms of the Creative Commons Attribution License (CC BY). The use, distribution or reproduction in other forums is permitted, provided the original author(s) and the copyright owner(s) are credited and that the original publication in this journal is cited, in accordance with accepted academic practice. No use, distribution or reproduction is permitted which does not comply with these terms. 